\title{
TRANSFORMACIÓN DEL PAISAJE URBANO DEBIDO A LA INCORPORACIÓN DE NUEVAS INFRAESTRUCTURAS EN LA PRIMERA MITAD DEL SIGLO XX EN CUENCA (ECUADOR)
}

\author{
María Augusta Hermida Palacios \\ Universidad de Cuenca, Cuenca, Ecuador \\ augusta.hermida@ucuenca.edu.ec \\ ORCID iD: https://orcid.org/0000-0003-1326-2723 \\ Pablo Armando León González \\ Universidad de Cuenca, Cuenca, Ecuador \\ pablo.leon@ucuenca.edu.ec \\ ORCID iD: https://orcid.org/0000-0002-5623-5437 \\ Andrea Daniela Cobo Torres \\ Universidad de Cuenca, Cuenca, Ecuador \\ daniela.cobot@ucuenca.edu.ec \\ ORCID iD: https://orcid.org/0000-0001-8000-7664
}

Recibido: 09/04/2020; Aceptado: 22/07/2021; Publicado: 12/12/2021

Cómo citar este artículo/citation: Hermida Palacios, María Augusta; León González, Pablo Armando y Cobo Torres, Andrea Daniela (2021). Transformación del paisaje urbano debido a la incorporación de nuevas infraestructuras en la primera mitad del siglo XX en Cuenca (Ecuador). Estudios Geográficos, 82 (291), e075. https://doi.org/10.3989/estgeogr.202186.086

RESUMEN: En la actualidad, el estudio del paisaje urbano ha adquirido relevancia técnica y científica. Las ciudades cambian y evolucionan constantemente, siendo las infraestructuras uno de los mayores modificadores del paisaje, luego de la agricultura y la urbanización. Durante el siglo XX los sistemas urbanos se ampliaron, se construía una infraestructura centralizada que se extendía conforme crecía la ciudad. El siglo XXI desafía a incorporar infraestructuras distribuidas y nuevas tecnologías como respuesta al cambio climático, que están transformando los paisajes urbanos y sobre los que se debe reflexionar. Para ello, es fundamental aprender del pasado e identificar cómo la incorporación de las infraestructuras y servicios influenciaron en la imagen de la ciudad, transformaron entornos naturales en urbanos y modificaron la forma de vida de sus habitantes. Esta investigación tiene por objetivo identificar los momentos significativos de transformación en el paisaje urbano en la primera mitad del siglo XX en la ciudad de Cuenca (Ecuador), asociados a la incorporación e innovación de infraestructuras y redes de servicios de agua, saneamiento y energía. Se utilizaron fuentes primarias, secundarias y fotografías históricas como herramientas para el análisis de las transformaciones en el paisaje. Los resultados evidencian que los años 20 marcaron un punto de inflexión con el inicio de una renovación modernizadora en el país y específicamente en Cuenca. El auge económico por la explotación de cascarilla y la exportación de sombreros de paja toquilla, se convirtió en motor para la incorporación de infraestructuras. Finalmente, se plantean interrogantes que deberán conducir a una exploración más profunda y a la toma consciente de decisiones frente a este tema en las ciudades.

PALABRAS CLAVE: paisaje urbano; infraestructuras; energías; formas de vivir; fotografía histórica.

\section{Urban landscape transformation due to new infrastructures incorporation during the first half of the twentieth century. The case of Cuenca (Ecuador)}

ABSTRACT: Currently, the study of the urban landscape has acquired technical and scientific relevance. Cities are constantly changing and evolving, and infrastructures are among the greatest modifiers of the urban landscape, after agriculture and urbanization. During the twentieth century, urban systems expanded, a centralized infrastructure was built, which broaden as the city grew. The twentieth-one century challenges to incorporate distributed infrastructures and new technologies in response to climate change, which are transforming urban landscapes and on which we must reflect. Thus, it is essential to learn from the past and identify how the incorporation of infrastructures and services influenced the city's image, transformed natural into urban environments, and modified the ways of living of its inhabitants. This research aims to identify the crucial moments of transformation in the urban landscape during the first half of the twentieth century in Cuenca (Ecuador), associated with the incorporation and innovation of infrastructures and services systems: water, sanitation, and energy. Primary and secondary sources and historical photos were used as tools to analyze urban landscape transformations. The results show that the 20's marked an inflection point with the beginning of a modernizing renovation in the country, specifically in Cuenca. Due to the exploitation of quinine and the exportation of Panama hats, the economic boom became the driving force for the incorporation of new infrastructures. Finally, questions are raised that should lead to a more profound exploration and conscious decision-making on this issue in cities.

KEY WORDS: urban landscape; infrastructures; energies; ways of living; historical photography. 


\section{INTRODUCCIÓN}

\section{Antecedentes}

En los últimos años la consideración del paisaje ha adquirido relevancia tanto en su vertiente científica como técnica y como expresión visual del patrimonio natural y cultural de las sociedades. Simultáneamente, tal como lo menciona Zoido (2006), las infraestructuras han sido identificadas como el tercer modificador del paisaje, después de la agricultura y la urbanización. Se las entiende como las instalaciones fundamentales que se encuentran tanto en superficie como soterradas, que sirven a una ciudad o barrio, y que dan facilidades de transporte de gente y bienes, energía, agua, entre otras. Particularmente, durante el siglo XIX y XX los sistemas urbanos se ampliaron y cambiaron; $y$, conjuntamente con otros sistemas posteriores, produjeron transformaciones en los paisajes urbanos, en los espacios domésticos y en los modos de vivir (Gürel, 2008).

El estudio de los aspectos del paisaje urbano y los agentes de cambio que han incidido directa e indirectamente en su transformación, permite tener mayor claridad y conciencia al momento de planificar y actuar en la ciudad. Para ello, es necesario hacer un análisis de la evolución de la ciudad, examinándola a través de diferentes épocas e interpretando adecuadamente sus transformaciones. Particularmente, será importante conocer las primeras infraestructuras implementadas, así como los tipos de energía utilizados que están descritos en medios impresos, fondos bibliográficos y colecciones fotográficas. A través del tiempo, estas fuentes han sido instrumentos visuales que dan cuenta de los momentos de cambio que produjeron innovaciones y saltos tecnológicos, muchos con dinámicas modificatorias del paisaje urbano y las formas de vivir de los habitantes de un determinado lugar.

\section{Objetivo del estudio}

Esta investigación, por tanto, tiene por objetivo identificar los momentos significativos de cambio y transformación en la ciudad de Cuenca en la primera mitad del siglo XX, asociados a la incorporación e innovación de infraestructuras y redes de servicios básicos de agua y saneamiento, así como a la implementación de diferentes formas de energía; entendidos como elementos y factores en la configuración urbana, que contribuyen a la modificación y transformación del paisaje urbano. Se busca describir el surgimiento de estos sistemas asociados a procesos de planificación urbana e interpretar la manera en la que influyeron en las formas de vivir de la sociedad. Mediante un análisis de los acontecimientos históricos, y la comparación por periodos de archivos fotográficos de la primera mitad del siglo XX, se presenta un panorama multidimensional de la evolución de las infraestructuras en el tiempo y, a través de esto, la transformación del paisaje urbano.

\section{Lugar de estudio}

Cuenca se localiza al sur de Ecuador, en la región interandina a 2550 metros sobre el nivel del mar. Es la tercera ciudad más grande del país en términos de población. Según el censo realizado por el Instituto Nacional de Estadísticas y Censos en el año 2010, la ciudad contaba con alrededor de 330000 habitantes (INEC, 2010), por lo que se estima que al año 2021 habría alcanzado aproximadamente los 600000 habitantes.

Cuenca en el transcurso de su desarrollo, ha sido moldeada por artesanos y albañiles, por sus pobladores y vecinos, quienes han plasmado la morfología urbana a través del tiempo, así como también por agentes de poderes establecidos que han configurado en el tiempo su aspecto (Borrero, 2006). Al igual que otras regiones de los Andes, Cuenca fue colonizada por españoles. Su fundación la llevó a cabo Gil Ramírez Dávalos en 1557 sobre las ruinas incas de Tomebamba y, posteriormente, en 1820 fue independizada.

Durante el siglo XIX la infraestructura urbana de Cuenca fue casi la misma que la de la época colonial. Las calles eran anchas y adecuadas para la circulación peatonal y de carruajes. De tanto en tanto se construía algún edificio, se hacía mantenimiento de lo existente $y$, en general, las obras que realizaba la administración municipal eran pequeñas (ibídem). A mediados del siglo XIX, la ciudad era descrita como una región incomunicada respecto al resto del país, donde prevalecía el sistema económico de propiedades rurales o minifundios; crecía lenta, manteniendo un desarrollo pausado sin grandes transformaciones. Para finales del siglo XIX, Cuenca se estableció como la tercera ciudad de la República, con una población de 20000 a 25000 habitantes. No poseía edificios públicos o privados notables, contaba apenas con una catedral, siete iglesias, una universidad incompleta y algunos otros servicios como un hospital y un orfanato (Brito y Espinoza, 2018).

La primera mitad del siglo XX tampoco fue de grandes cambios. La ciudad presentaba un aislamiento geográfico debido a la situación deplorable de las 
carreteras y la ausencia de caminos que la conecten con otros asentamientos (Lloret, 2015). La comunicación no solo física sino también informativa era escasa. Durante este periodo, la difusión de noticias y acontecimientos nacionales e internacionales estaba limitada a la prensa escrita, y el desarrollo de los medios de comunicación era lento. Para 1930 esta condición cambió gradualmente con la introducción de la radio y, posteriormente, del teléfono (Novillo, 2010). En cuanto a lo económico, inicialmente las necesidades se solventaban con la agricultura y la ganadería, aunque las condiciones climáticas no eran las mejores (ibídem). Después, surgió la manufactura de sombreros de paja toquilla y la explotación de los bosques de cascarilla en beneficio de las colonias británicas que la requerían para enfrentar la malaria. Esto generó las primeras fortunas de algunas familias y el inicio de la incorporación de infraestructura en la ciudad; no obstante, también provocó tensiones sociales que influyeron en el lento crecimiento de Cuenca (Cuenca, su historia: al paso de los siglos XIX y XX, 2014).

A pesar de todo esto, los años 20 marcan el inicio de una transformación modernizadora en diferentes ámbitos: culturales, económicos, sociales y tecnológicos. Se observa que Cuenca y otras ciudades del país comienzan a alumbrarse utilizando energía eléctrica, acogiendo los avances de la ciencia. La modernización de la ciudad en este periodo estuvo vinculada no solo con las distintas formas de transporte, sino además, con toda una infraestructura que mejoraría las condiciones de vida de la población (Marchán, 1987). De esta manera, la llegada de la energía eléctrica, el agua potable y las redes de alcantarillado van transformando el paisaje urbano (Mancero, 2010). Este momento socio-económico genera una nueva élite económica y cultural que fue fundamental en la transformación de la arquitectura y las infraestructuras en Cuenca (ibídem).

\section{ANTECEDENTES TEÓRICOS}

\section{Paisaje y paisaje urbano}

Ha sido difícil estructurar un discurso concluyente en torno a la noción de paisaje (Moreno, 2009; ZubeIzu y Allende, 2015). Existe una multitud de posturas desde las diferentes disciplinas, en donde subyacen nociones sobre las que se han construido diversas definiciones. Sin embargo, en forma genérica se diferencian dos vertientes: la anglosajona que se ha ocupado del paisaje desde su concepción como hecho espacial y ambiental, centrada en el estudio y manejo de los componentes físicos del territorio; y por otro, la tradición Europea-Mediterránea, que algunos autores la denominan latina, y centra su atención en la dimensión social y cultural del paisaje como expresión estética de las formas de vida de los habitantes en un determinado contexto espacial y temporal (Moreno, 2009, p. 5-6).

Históricamente, en las primeras definiciones de paisaje, este se asociaba a un término puramente estético-pictórico (Claval, 2012; Sansolo, 2007), una forma de representación escénica, un espacio observado, una forma de marco en el que los personajes tenían un papel secundario (Fürstenau, 2009). Recién iniciado el siglo XX, es superada esta noción artística o estética (Zoido, 2012) para ser entendido como una dimensión de lo visible y resultado de una producción de actividades y acciones humanas (Troll, 1963). Acciones que han logrado influenciar decisivamente en la formación de la estructura y funcionamiento del entorno (Spedding, 2003; ibídem).

Así, para Ferrer (2009) el paisaje "urbano" puede ser entendido como el producto de una serie de transformaciones producidas en su mayoría por planes y proyectos urbanos, actuaciones arquitectónicas y acciones diversas concernientes con la organización de los espacios, la disposición del mobiliario urbano, la energía, la implementación de elementos técnicos, etc. (41). Puesto que las ciudades han atravesado por un proceso para acoplarse al espacio geográfico en el cual se emplazan, transformando un entorno natural en uno urbano, este entorno da cuenta de la forma de ser y hacer de una determinada sociedad en el tiempo y espacio (Astudillo, 2008). Así mismo, este entorno se trata de un constructo social e histórico que otorga a cada ciudad un carácter propio e identificable desde su imagen visual (Rodas, Astudillo y Rodas, 2018). Por lo tanto, la noción de paisaje urbano se compone de diferentes elementos del sistema urbano y de su entorno. Estos elementos al ser dinámicos y complejos, materiales e inmateriales, cambian y evolucionan a través del tiempo por diversas condicionantes, entre ellas las tecnológicas, económicas, sociales y culturales (Vintimilla, 2019).

\section{Fotografía del paisaje como registro}

A partir de finales del siglo XIX, se teoriza sobre la importancia e interpretación que la imagen adquiere como documento histórico, y se instaura la noción de los archivos fotográficos como fuente de valor documental y de carácter historiográfico. Desde consideraciones positivistas, la fotografía fue estimada como do- 
cumento ideal e instrumento fiel e imparcial de reproducción de la realidad, a la que se otorgaba un valor documental equiparable a documentos escritos. A finales de los años 60 la imagen fotográfica empieza a destacar como una fuente útil, que permite desarrollar el planteamiento de nuevos enfoques interpretativos para la investigación histórica (Manfredi, 2008). Proporciona una nueva significación a la idea de información, su valor radica en ser evidencia y testigo de ciertos puntos de vista del pasado, y de un tiempo pasado (Burke, 2001); es entendida como un medio que nos acerca a los acontecimientos, aunque estemos separados temporal y espacialmente. De este modo, las imágenes vistas como una demostración de los hechos, permiten construir una memoria histórica, una muestra de ciertos aspectos del pasado a los que quizá otros tipos de fuentes no llegan. Resulta bastante útil recurrir a ellas para entender cómo los espacios han cambiado con el tiempo, sobre todo cuando los textos son escasos o no proporcionan suficiente información (ibídem).

Varios autores han utilizado imágenes incluyendo fotografías históricas y postales como herramientas para entender los cambios del paisaje en el entorno urbano (Arreola y Burkhart, 2010; Foote, 1985; Foote, 1986; Notteboom, 2011; Page, 2007). El trabajo desarrollado por Foote $(1985,1986)$ por ejemplo, demuestra que la fotografía puede emplearse inclusive como fuente primaria para el análisis de los cambios en el paisaje, además, sirve para medir el grado y la velocidad de estos cambios si se utilizan datos y métodos adecuados. En otros casos, se han empleado métodos de re-fotografía para investigar los cambios del paisaje urbano como en San Francisco (Klett y Lundgren, 2006) o en el territorio belga (Notteboom y Uyttenhove, 2018). En la misma línea, este documento parte de una comparación entre imágenes fotográficas producidas en épocas distintas de la primera mitad el siglo XX en Cuenca, configurándose como un trabajo metodológico de carácter historiográfico para entender los cambios del paisaje urbano producidos durante este periodo.

\section{Infraestructura}

Existe una estrecha relación de carácter histórico entre paisaje e infraestructura. Entre ambos elementos se ha producido un largo proceso de interacción, puesto que las infraestructuras han sido modificadores fundamentales del paisaje, de entornos naturales a urbanos (Zoido, 2006).

En este estudio, se entiende por infraestructuras a aquellas instalaciones fundamentales que sirven a una ciudad o barrio, que se encuentran tanto en su- perficie como soterradas; aquellas que más allá de su ubicación, están dispuestas para dar facilidades de transporte de gente y bienes, energía, agua, entre otras. Las infraestructuras desde su inicio han sido factores fundamentales en la configuración del paisaje urbano. Se han tornado en referentes que nacen de los mecanismos y procesos que se desarrollan en diferentes escalas espaciales y en distintos tiempos, por lo que se constituyen en espejo de la traza urbana y su evolución. A la par, la tecnología incorpora técnicas específicas que singularizan los paisajes urbanos y modifican prácticas sociales y espacios de vida de un determinado lugar (ibídem). Así, se sustenta la condición dinámica del paisaje urbano y la relación causal de las infraestructuras sobre él, en una perspectiva histórica que resulta valiosa para expresar sus transformaciones y evoluciones.

\section{FUENTES Y METODOLOGÍA}

Para el análisis de las transformaciones en el paisaje urbano de Cuenca durante la primera mitad del siglo $X X$, se partió de una periodización de los acontecimientos en torno a la llegada y evolución de las infraestructuras y la tecnología, ya sea por incorporación, innovación, reposición, u otras. Para ello, se utilizaron como fuentes primarias los archivos públicos fotográficos de varios fondos: a) Fondo Fotográfico del Museo Pumapungo, con alrededor de 9000 fotografías organizadas por décadas pero sin criterios específicos de selección; b) Fondo Nacional de Fotografía (http://fotografiapatrimonial.gob.ec) con cerca de 2700 fotografías relacionadas al tema y ordenadas por fechas que pueden ser seleccionadas por criterios de búsqueda, palabras clave y temáticas asociadas al título original de la foto; c) Colección periódica de revistas divulgativas municipales históricas - Revista 3 de Noviembre- que se configuró como instrumento histórico de primera mano para corroborar fechas en eventos y sucesos fundamentales. Además, se utilizaron fuentes secundarias como publicaciones en periódicos - La Crónica, El Mercurio, La Alianza Obrera-, datos encontrados en libros, entrevistas y otras fuentes bibliográficas documentales como tesis de pregrado y posgrado. Los datos encontrados en estas fuentes permitieron confirmar y validar fechas referidas a cada momento histórico de saltos cualitativos o cambios significativos. Posteriormente, se elaboró una línea histórica entendida como una cronología comparada que vincula la evolución de los diferentes ámbitos de estudio.

Finalmente, en base a una línea temporal-gráfica se mostraron los cambios sucesivos que cada una de las 
FIGURA 1.

AVENIDA FRAY VICENTE SOLANO Y CALLE SIMÓN BOLÍVAR, CUENCA

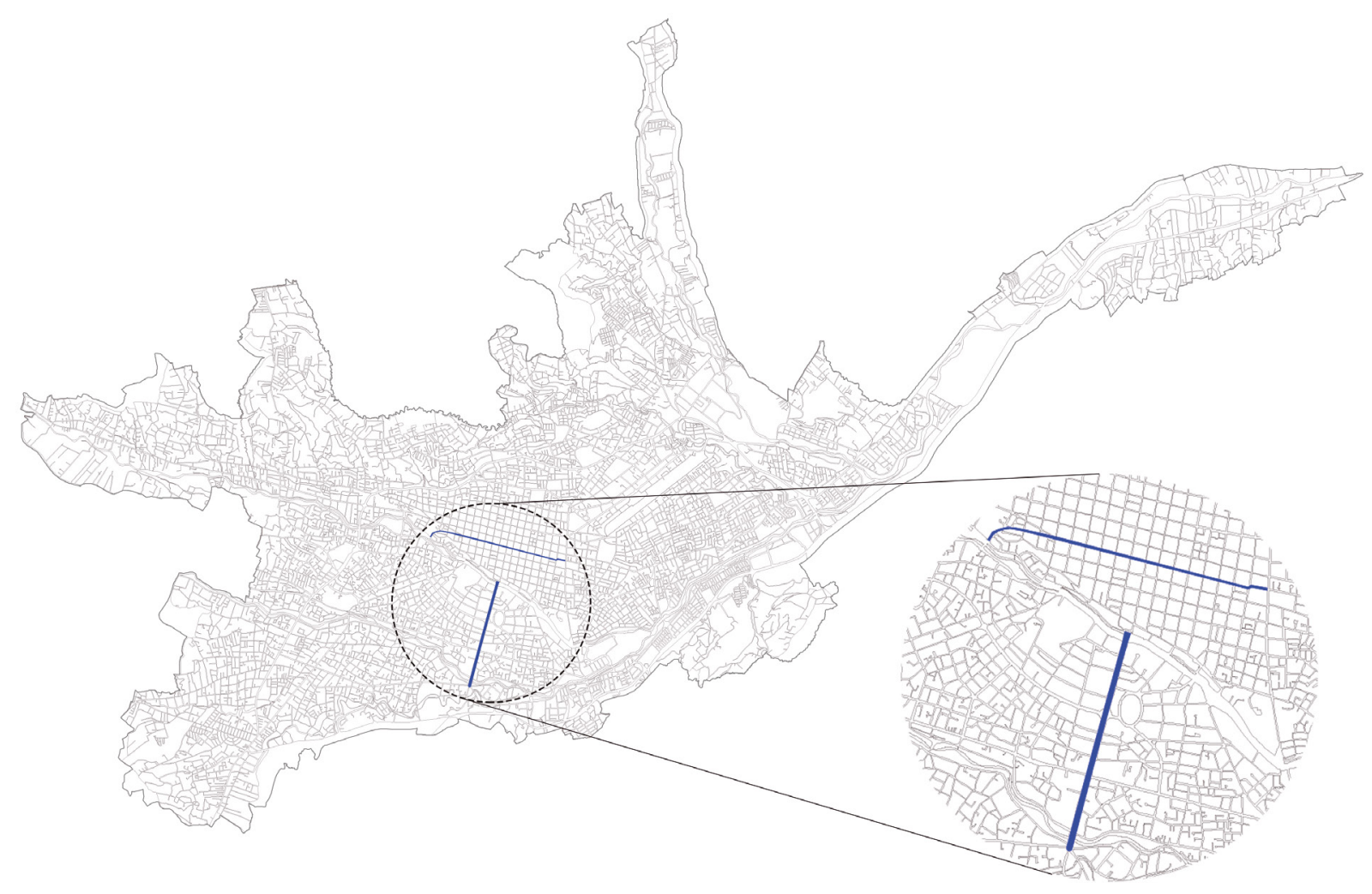

Fuente: Ilustre Municipalidad de Cuenca. Elaboración propia.

infraestructuras y tecnologías han tenido a través del tiempo, partiendo de una identificación por imágenes de calles en distintas temporalidades. Asimismo, se hizo una caracterización de la evolución de los servicios e infraestructuras, se describieron las características morfológicas y formales, y se definieron los momentos históricos de cambio relevante. Para profundizar el análisis, se decidió seleccionar dos ejes que atraviesan la ciudad y que, a lo largo del tiempo, han sido calles importantes, concurridas y fotografiadas, lo que posibilita ilustrar las transformaciones espaciotemporales. Los ejes estudiados fueron la calle Simón Bolívar que recorre la ciudad de este a oeste y se ubica en el centro histórico, y la avenida Fray Vicente Solano que se extiende de norte a sur, conectando el centro histórico de Cuenca con la ciudad baja conocida como El Ejido (Fig. 1).

\section{RESULTADOS}

El trabajo se aproxima a dos dimensiones para situar las claves que conforman el paisaje de la ciudad a inicios del siglo XX. Por un lado, los cambios se interpretan a la luz del proceso de desarrollo urbano y sus pautas de crecimiento que reflejan los trazos históricos de una ciudad (Rueda, 2001); y por otro, la imagen histórica urbana que permite una cronología que pauta el lento paso a la modernidad y que irá advirtiendo el impacto de las infraestructuras desde finales del siglo XIX hasta mediados del siglo XX en el paisaje urbano.

\section{Acontecimientos históricos en la primera mitad del siglo XX en Cuenca}

El momento económico que vive Cuenca a inicios de siglo, producto de las exportaciones del sombrero de paja toquilla y la explotación de la cascarilla (Martínez, 2004), crea las primeras fortunas de algunas familias cuencanas y esto significó la mejora económica para ciertos grupos sociales, lo que tuvo como consecuencia la renovación urbana. Esta nueva élite económica y cultural, en un momento político impulsado por los ideales liberales, desarrolla una visión "moderna" de la sociedad, y constituye un momento fundamental de transformación de la ciudad y de las infraestructuras. Cuenca, se convierte en una ciudad en la que se impulsa y prioriza la obra pública y se da 
FIGURA 2.

CALLES MALO Y JARAMILLO, 1930. SISTEMA DE ILUMINACIÓN A COMBUSTIBLE

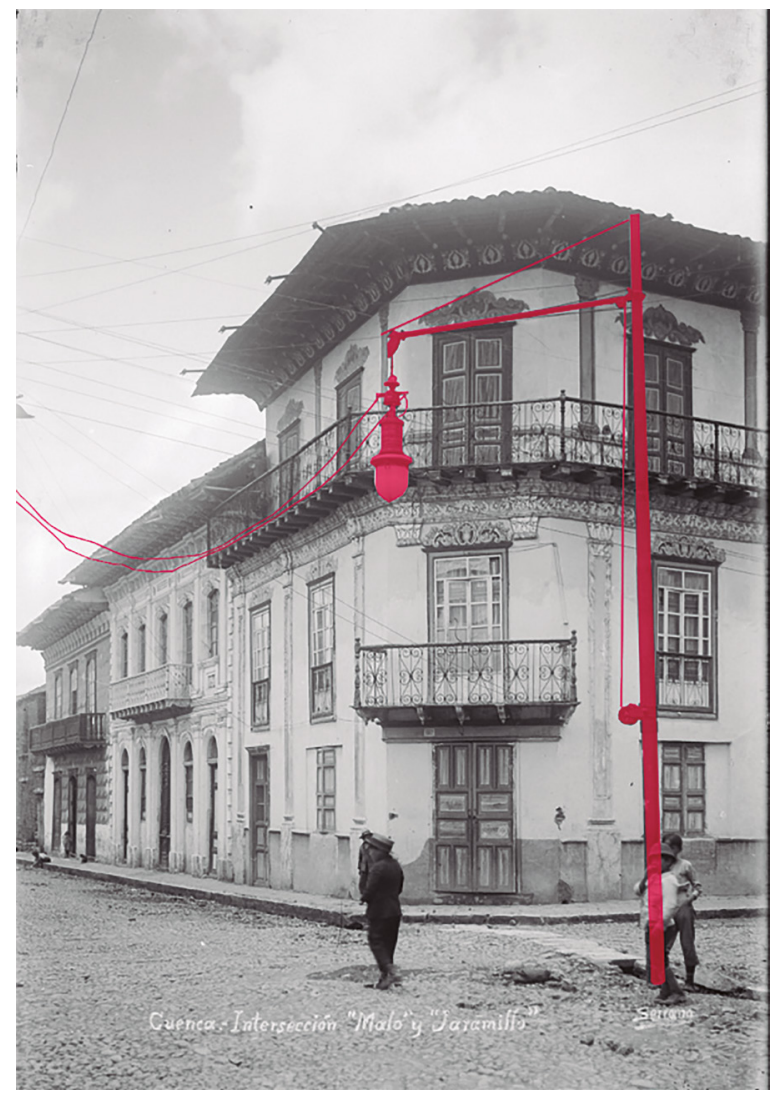

Fuente: Fondo Histórico Fotográfico Museo Pumapungo.

una acelerada aplicación de las tecnologías y la técnica para resolver problemas elementales (ibídem). Se destinan recursos para modernizar el entorno urbano $y$, aunque lentamente, la ciudad incursiona en el progreso técnico con eventos importantes como la llegada del primer automóvil en 1913, la inauguración de la planta eléctrica en 1914, la implementación de los planes de alcantarillado, sistemas de potabilización y el aparecimiento de numerosas construcciones nuevas.

Por otro lado, el aumento de la población urbana hizo necesario el urgente acceso a servicios básicos, mientras la creciente demanda de energía se configuró en la impulsora de las transiciones energéticas. Como consecuencia, la dotación de estos servicios considerados modernos, imprimen su marca en el paisaje de la ciudad. Estos acontecimientos modifican paulatinamente el aspecto de Cuenca, su paisaje urbano y la forma de vida de sus habitantes. La línea del tiempo (Tabla 1), resume lo sucedido desde inicios hasta mediados del siglo XX en la ciudad.
FIGURA 3.

CALLE BOLÍVAR, 1930. SISTEMA DE CONDUCCIÓN ELÉCTRICO AÉREO

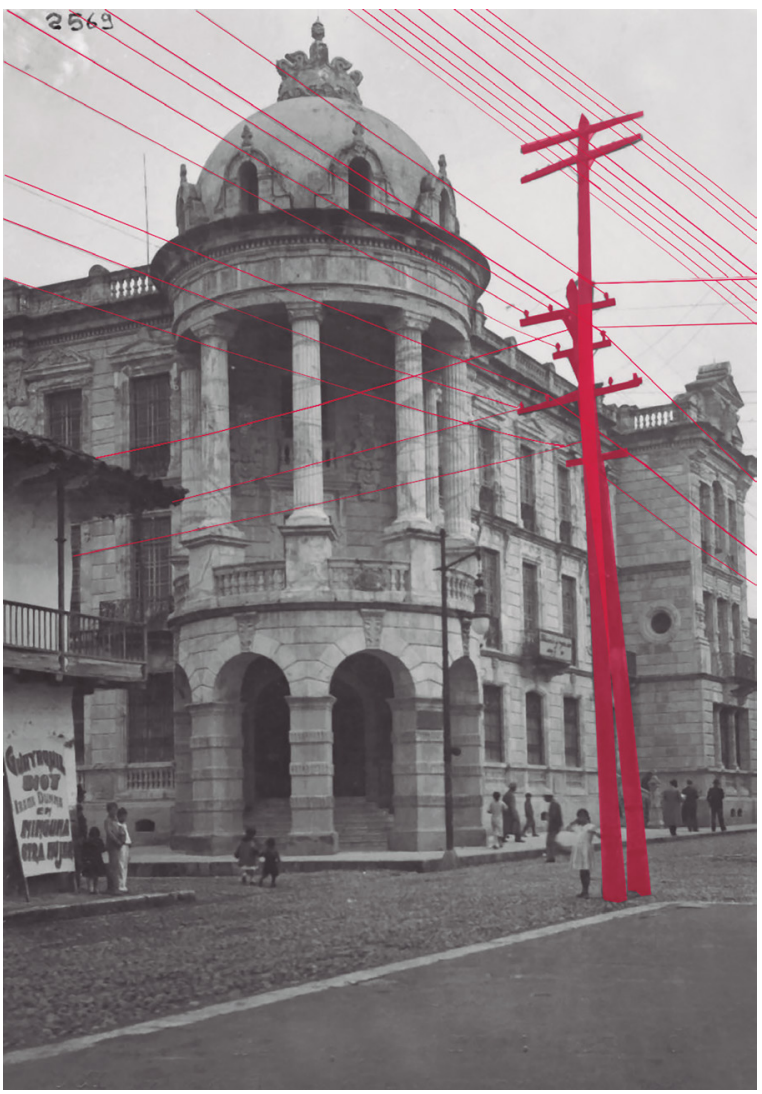

Fuente: Fondo Histórico Fotográfico Museo Pumapungo.

\section{Energía eléctrica y agua a inicios del siglo XX en Cuenca}

Durante este periodo, se observan en la ciudad tres etapas o momentos en las formas de conducción de electricidad. En un momento inicial, la iluminación pública se normó con la incorporación de lámparas de petróleo en cada casa, que debían ser prendidas por los propietarios a ciertas horas y en días específicos. Luego, los sistemas de iluminación pública incorporaron lámparas ornamentales a base de combustible sobre postes metálicos, distribuidos estratégicamente en las calles (Fig. 2). En un segundo momento, estos sistemas de iluminación empezaron a coexistir con la incipiente generación eléctrica de plantas móviles que funcionaban con combustible e hidroeléctricas; siendo estos los pioneros sistemas de generación de energía que surgen de la iniciativa privada, para abastecer sectores industriales y selectos sectores urbanos. Por último, en el tercer momento, se da una transición gradual hacia las centrales eléctricas municipales y estaciones de transferen- 
TABLA 1.

LÍNEA DEL TIEMPO: TECNOLOGÍA, INFRAESTRUCTURAS Y PLANIFICACIÓN

\begin{tabular}{|c|c|}
\hline Periodo & Acontecimientos \\
\hline \multirow[t]{4}{*}{$\begin{array}{l}1900- \\
1910\end{array}$} & $\begin{array}{l}\text { 1900.- La provisión de agua consiste en el empleo de pozos subterráneos. Las pilas públicas y el agua acarreada del río constituyen otra fuente de } \\
\text { provisión de agua. El estado sanitario es muy precario, niños y adultos están infectados con bacterias y varias enfermedades. }\end{array}$ \\
\hline & $\begin{array}{l}\text { 1907.- Entra en vigencia la iluminación con lámparas de petróleo mediante ordenanza. Los propietarios se encargan de iluminar las fachadas de } \\
\text { sus casas. }\end{array}$ \\
\hline & $\begin{array}{l}\text { 1909.- Las primeras pilas públicas de hierro fundido son importadas desde Alemania. Las casas no disponen de inodoros, se usan bacinillas de } \\
\text { hierro enlozado y de arcilla cocida. }\end{array}$ \\
\hline & 1910.- Todos los desechos de las familias son expulsados directamente a las acequias durante la noche. \\
\hline \multirow{8}{*}{$\begin{array}{l}1911- \\
1920\end{array}$} & 1911.- Existen alrededor de 76 manzanas consolidadas en la ciudad de Cuenca, con un tamaño aproximado de $80 \mathrm{~m} \times 80 \mathrm{~m}$ cada una. \\
\hline & 1913.- Llega el primer automóvil a Cuenca. \\
\hline & 1914.- Se inaugura la primera planta eléctrica. \\
\hline & $\begin{array}{l}\text { 1915.- Los cuencanos se asean en las aguas del Río Tomebamba al no disponer de baños. La mayoría de casas cuentan con huerto, el cual también } \\
\text { se usa para la evacuación de desperdicios. }\end{array}$ \\
\hline & 1920.- Se canalizan y adoquinan algunas calles. \\
\hline & 1920.- La avenida Fray Vicente Solano aparece por primera vez en un plano. \\
\hline & 1920.- La ciudad vive un afrancesamiento de sus fachadas y edificios. \\
\hline & 1920.- Llega el primer avión a Cuenca. \\
\hline \multirow{13}{*}{$\begin{array}{l}1921- \\
1930\end{array}$} & 1922.- Gente muy ilustre de Cuenca instaura el ideal de traer el agua hacia la colina de Cullca para tratarla. \\
\hline & 1924.- Entra en vigencia la Ordenanza que permite rodar carros en Cuenca. \\
\hline & $\begin{array}{l}\text { 1924.- Se hace una convocatoria para la ejecución de la obra de canalización y dotación de agua potable. Se realizan distintos análisis de calidad } \\
\text { del agua del río Sayausí. }\end{array}$ \\
\hline & 1924.- Se difunde el servicio de teléfono. \\
\hline & 1924.- Se espera contar con alumbrado de focos de mil bujías. \\
\hline & 1925.- Se construyen las cloacas Oeste - Este y los canales subterráneos de las calles: Lamar, Simón Bolívar y Gran Colombia. \\
\hline & 1925.- Se compite entre empresas de electricidad por ofrecer el servicio y productos como focos de 15 y 25 vatios. \\
\hline & 1925.- Se instala el servicio de luz de mil vatios en la parte oriental de la ciudad. \\
\hline & 1926.- Se inaugura la planta hidroeléctrica de Monay. \\
\hline & 1929.- Se otorga la primera subvención para la construcción de infraestructura de agua potable. \\
\hline & $\begin{array}{l}\text { 1930.- La imagen de la ciudad se transforma, se han optimizado los servicios de agua y luz. El servicio de agua potable entra en vigencia } \\
\text { aprovechando las aguas del Río Capulí. }\end{array}$ \\
\hline & 1930.- La avenida Fray Vicente Solano cuenta con dos carriles. \\
\hline & 1930.- Aparece la radio, sintonizaba una o dos emisoras. \\
\hline \multirow{6}{*}{$\begin{array}{c}1931- \\
1940\end{array}$} & 1931.- El primer inodoro de loza blanca con cadena es traído por una reconocida familia de la ciudad. \\
\hline & 1931.- Comienzan a rodar motocicletas. \\
\hline & 1932.- Los trabajos de canalización avanzan pero las casas no disponen de lugares adecuados para colocar los servicios higiénicos. \\
\hline & 1934.- Los primeros cuartos de baño se sitúan en incómodos locales: bajo la grada, en las esquinas y en los traspatios de las casas. \\
\hline & $\begin{array}{l}\text { 1936.- Aproximadamente } 700 \text { usuarios gozan del servicio de agua potable. Sin embargo, debido al crecimiento de la población, se dispone el } \\
\text { cambio de tubería de } 5 \text { a } 10 \text { pulgadas en los tanques de Cullca. }\end{array}$ \\
\hline & 1936.- La Municipalidad instala servicios higiénicos públicos en la ciudad dotados de inodoros, duchas y lavabos, división para hombres y mujeres. \\
\hline \multirow{8}{*}{$\begin{array}{l}1941- \\
1950\end{array}$} & 1942.- Se presenta el primer planteamiento de ensanchamiento para la ciudad. \\
\hline & 1947.- Se construye la planta hidroeléctrica con fuente de captación en el Río Machángara. \\
\hline & 1947.- Se plantea un proyecto de agua potable para abastecer a aproximadamente 55000 habitantes. \\
\hline & 1947/1951.- Se dota de servicio en las áreas rurales. \\
\hline & $\begin{array}{l}\text { 1949.- Se presenta el Plan Regulador de Gilberto Gatto Sobral. Se cuenta con calles principales pavimentadas, servicios de agua y alumbrado que } \\
\text { se extienden día a día a toda la población. }\end{array}$ \\
\hline & 1950.- Se constituye la Empresa Eléctrica Regional Centro Sur. \\
\hline & 1950.- Se concluye la construcción de la avenida Fray Vicente Solano. \\
\hline & 1952.- Se construye la planta de tratamiento del Cebollar con aireadores, cámaras de coagulación, tanques de sedimentación y de cloración. \\
\hline
\end{tabular}

Fuente: Periódicos La Crónica, El Mercurio, La Alianza Obrera (1900-1952). Elaboración propia. 
FIGURA 4.

FACHADA ESCUELA SAN JOSÉ, 1943. SISTEMA DE CONDUCCIÓN POR EMPOTRAMIENTO EN FACHADA

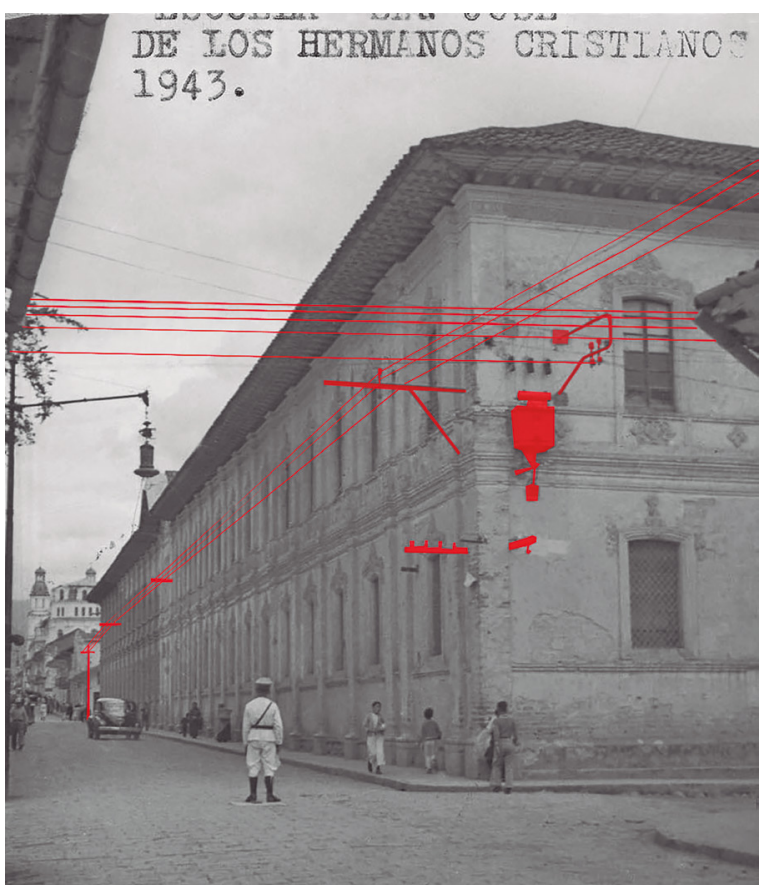

Fuente: Fondo Histórico Fotográfico Museo Pumapungo. cia eléctrica. Se incorporan elementos como postes que se emplazan en la traza de calles empedradas para tráfico de caballos y carretas (Fig. 3). Finalmente, esta etapa deriva en la inclusión de sistemas en las fachadas, y en cables elevados en redes de alta tensión que afectan profundamente la configuración del espacio urbano (Fig. 4).

En cuanto al agua y su manejo en la ciudad a inicios del siglo XX, ha sido importante analizar por separado los avances concernientes con la dotación de agua potable, por un lado, y por otro, el tratamiento de aguas servidas y alcantarillado.

Así, durante los primeros años del siglo, Cuenca carecía de agua potable y, en general, las infraestructuras para el aprovisionamiento y conducción de agua se desarrollaban con lentitud. La ciudad contaba con un precario abastecimiento y suministro de agua corriente, que en muchos casos, debía ser traída por servidumbre que la acarreaba en recipientes de los ríos o de fuentes próximas (Fig. 5). En otros casos, las familias adineradas se abastecían de agua de pozos al interior de sus residencias.

Las acequias eran parte de las redes de distribución domiciliaria conducidas entre predios interio-

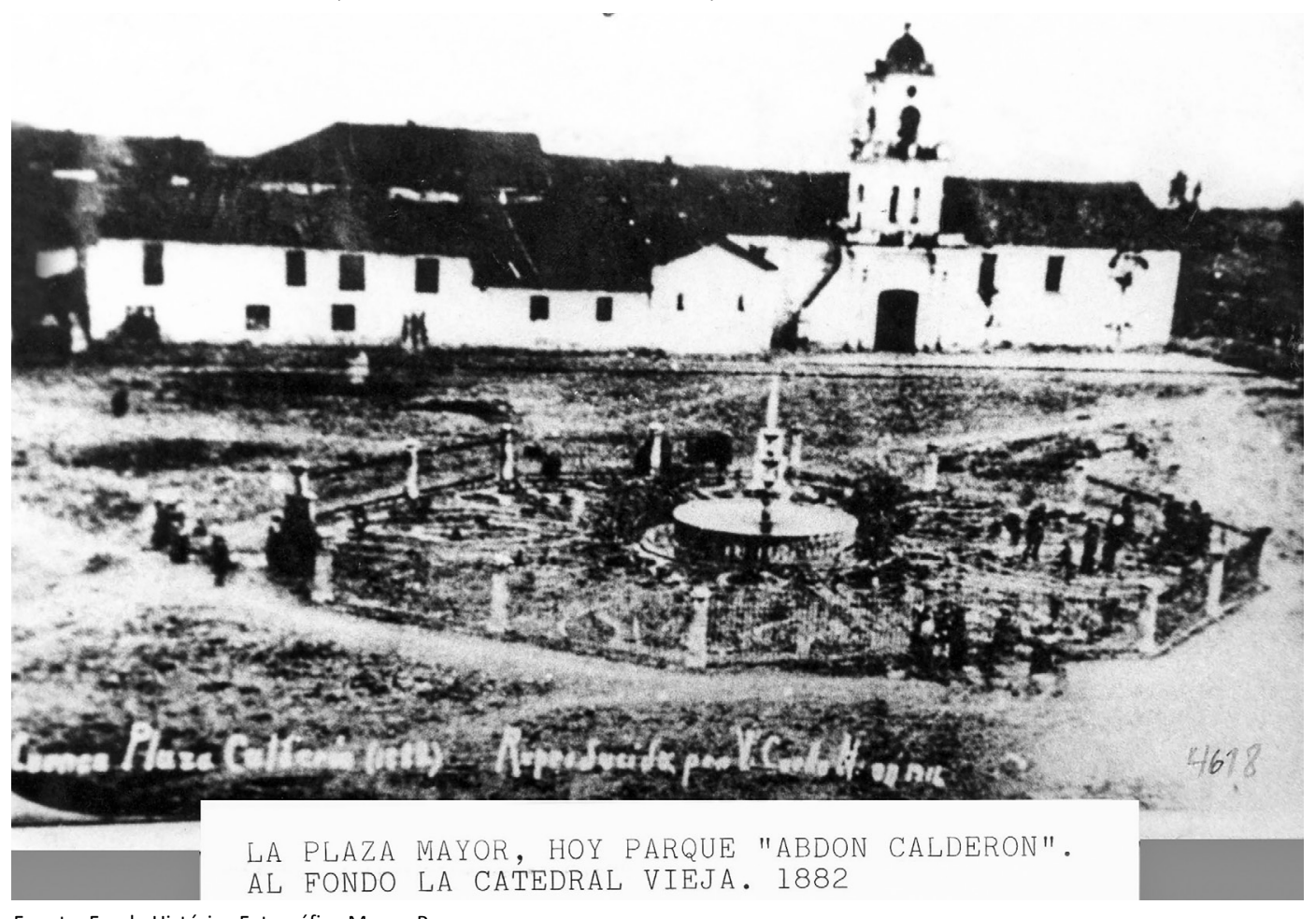

Fuente: Fondo Histórico Fotográfico Museo Pumapungo. 
FIGURA 6.

CALLE DEL CHORRO, ACTUAL CALLE ANTONIO BORRERO, 1890-1900. ACEQUIA EN MEDIO DE LA CALLE

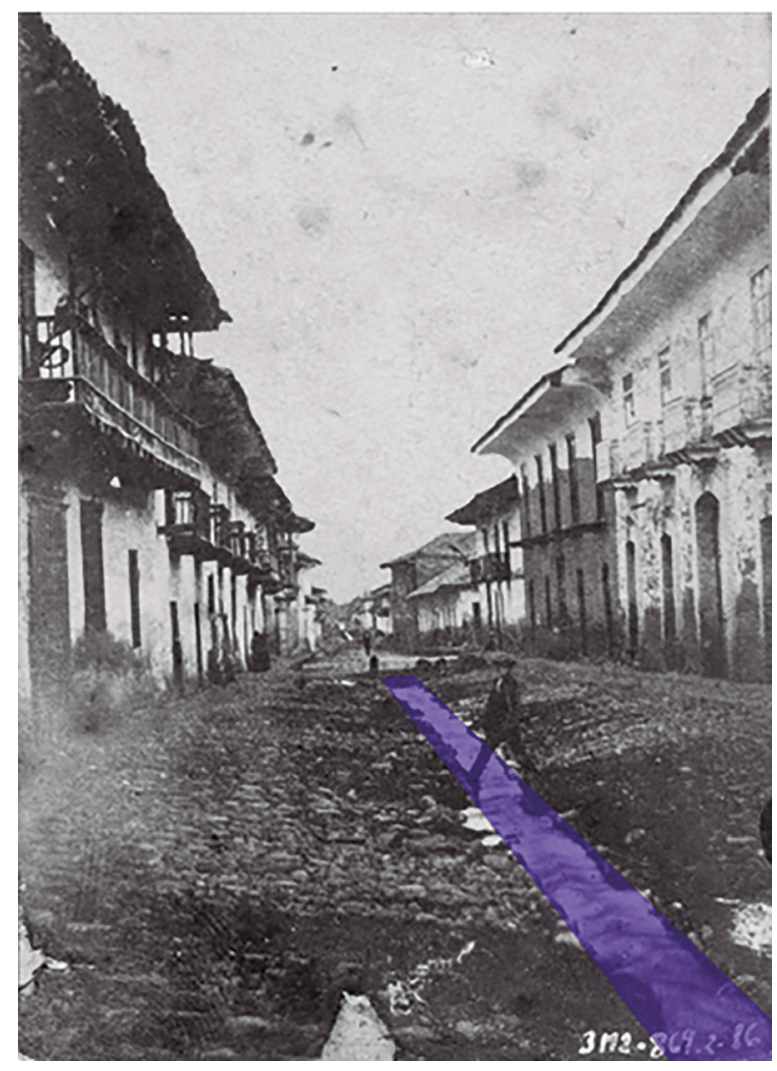

Fuente: Fondo Histórico Fotográfico Museo Pumapungo.

res; además, existían canales a cielo abierto y en medio de las calles que conducían agua cruda sin tratar. El agua llevaba consigo basura ocasionando problemas sanitarios graves (Fig. 6). Ante la demanda de necesidades sanitarias de toda la población, las autoridades pusieron atención al control de enfermedades y epidemias. Introdujeron una cultura de higiene, enfatizando la limpieza de acequias y destinando personal que controle la limpieza y el cumplimiento de los horarios de abastecimiento (Kingman, 2006). También debían controlar los caudales de ingreso y que las medidas de aprovisionamiento sean legales al interior de las viviendas. En busca de optimizar las condiciones sanitarias, se dieron grandes avances tecnológicos relacionados con el manejo y tratamiento de las aguas para consumo, así como en el aprovisionamiento mediante redes especializadas. En general, la incorporación de sistemas de distribución de agua fue relativamente fácil si se compara con los problemas que surgieron para resolver el tema de la evacuación de desechos.
FIGURA 7.

CALLE GRAN COLOMBIA, 1938. DESAPARECEN LAS ACEQUIAS, ENTRA EN VIGENCIA EL SERVICIO DE AGUA POTABLE

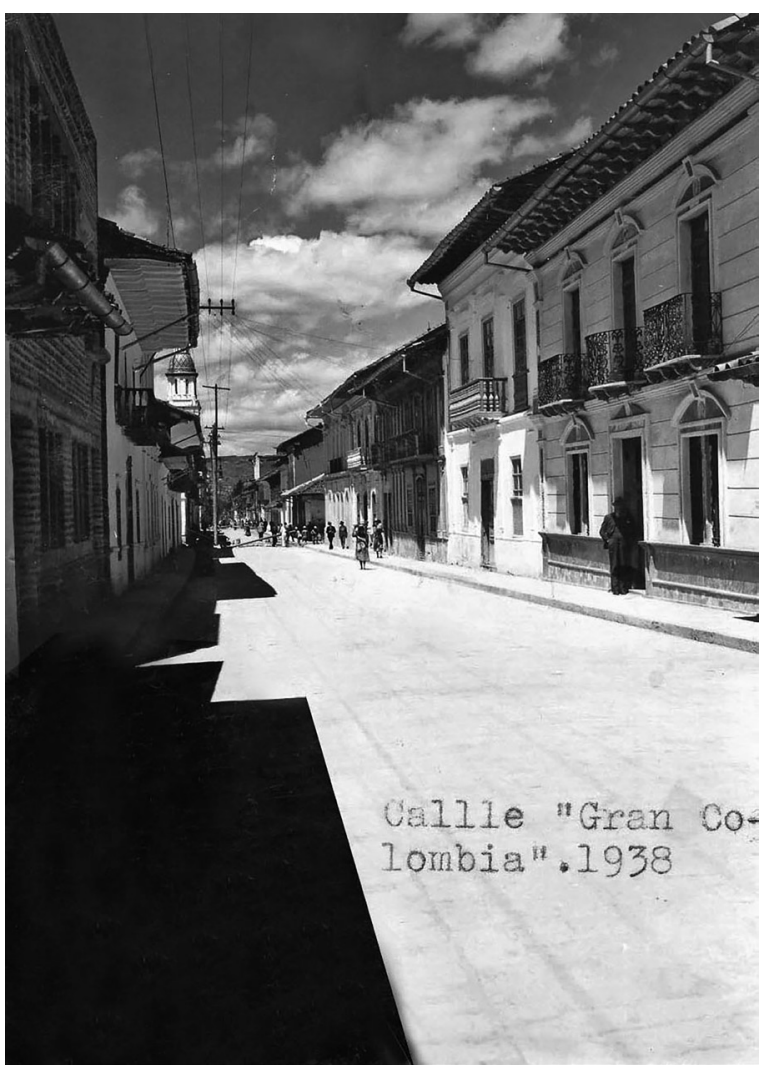

Fuente: Fondo Histórico Fotográfico Museo Pumapungo.

Cuenca a inicios del siglo XX carecía de alcantarillado y la forma de tratar los desechos era precaria. Tenía graves problemas de evacuación ya que sus desechos eran expulsados en las acequias y ríos más cercanos (Brito y Espinoza, 2018). En un primer momento, el canal de desechos discurría simultáneo en el mismo cauce de aprovisionamiento a superficie, alterando las condiciones higiénicas urbanas por la situación insalubre en las zonas de recorrido. Este factor fue fundamental en la modificación de la imagen de la ciudad. Todas las calles de Cuenca contaban con una acequia para el aseo, sus aguas iban de occidente a oriente y, la calle Simón Bolívar en particular, tenía dos de estos canales como veremos más adelante. Aquí, se arrojaban los desechos produciendo olores desagradables, especialmente durante las horas de aseo de los bacines (ibídem). En un segundo momento, se incorpora el sistema de canales cubiertos que conducían por vía subterránea los desperdicios sólidos que circulaban en las calles. Luego, estos se trasladaban a puntos lo suficientemente alejados del área urbana 
para su evacuación final. Un tercer momento sucede simultáneamente con la construcción de las calzadas (Fig. 7). Se evidencia que inicialmente los cauces centrales de conducción se cubren, y luego se desplazan a los laterales para recolectar las aguas lluvias.

Hasta aquí, se ha hecho un recuento histórico de los acontecimientos suscitados en Cuenca durante la primera mitad del siglo $X X$, haciendo énfasis a la dotación de electricidad y agua, y el servicio de recolección de aguas servidas y alcantarillado. Sin embargo, es importante analizar más detalladamente cómo estos sucesos han transformado el paisaje urbano y, para ello, serán referencia los dos ejes antes mencionados.

\section{La calle Simón Bolívar y la avenida Fray Vicente Solano}

Los ejes analizados se ubican en dos sectores claves de la ciudad, el denominado centro histórico y El Ejido. En ellos se han identificado las transformaciones significativas del paisaje urbano resultado de los acontecimientos históricos suscitados en la primera mitad del siglo XX. En el centro histórico, se trabaja con la calle Simón Bolívar, mientras que en el sector de El Ejido, se analiza la avenida Fray Vicente Solano.

En el plano anónimo de 1910 (Fig. 8), se visualiza la traza colonial basada en el damero, la cual se modifica en la unión con el río Matadero (actual río Tomebamba). En este plano, los límites de la ciudad son: al norte la calle Real del Vecino, antes calle Sandes; al sur el río Matadero y la avenida 3 de Noviembre; al oeste la iglesia Corazón de Jesús; y al este la actual avenida Huayna Capac (Albornoz, 2008). Además del centro consolidado, en el plano se evidencian los ejes fundamentales de conectividad que definirán zonas de futura expansión. Entre ellos se identifica a la avenida Loja al suroeste, que marca el encuentro con el sur (1), y la avenida Fray Vicente Solano que se extiende hacia la zona de El Ejido (2). En el sector del Rollo se ubica otro camino de primer orden hacia el norte (3), y la calle Simón Bolívar que se une con la Gran Colombia al oeste para dirigirse hacia Guayaquil (4).

Además de ser ejes de expansión, tanto la calle Simón Bolívar como la avenida Fray Vicente Solano son particularmente importantes por varios aspectos. La calle Simón Bolívar, se desarrolla en el lado norte de la plaza central (manzana con pileta en medio y distribución radial de ocho polígonos), conectando las iglesias de San Sebastián al oeste y de San Blas al este, y sus respectivas plazas. A lo largo de esta calle, se ubican otras edificaciones y espacios importantes como la iglesia del Cenáculo, la Plaza Central y el Convento. Esta calle se constituye como eje articulador que surge con la trama misma de la plaza, siendo fundamental en el trazado urbano. En ella, se evidencian cambios sucesivos por sustitución de infraestructuras a lo largo del siglo que serán explicadas en las imágenes posteriores. Esta calle ha sido relevante para la ciudad no solo por su función articuladora, sino también por su valor simbólico ya que en ella se desarrollan regularmente desfiles cívicos, actos religiosos y tradicionales como el Pase del Niño Viajero, y manifestaciones de toda índole. Con el pasar del tiempo, las edificaciones que se ubican en la calle han ido cambiado su uso residencial, por nuevos usos acordes al desarrollo de la urbe.

Por su parte, la avenida Fray Vicente Solano se ubica en la terraza baja conocida como El Ejido, que en el pla-

FIGURA 8.

PLANO DE 1910-1930 Y EJES DE EXPANSIÓN
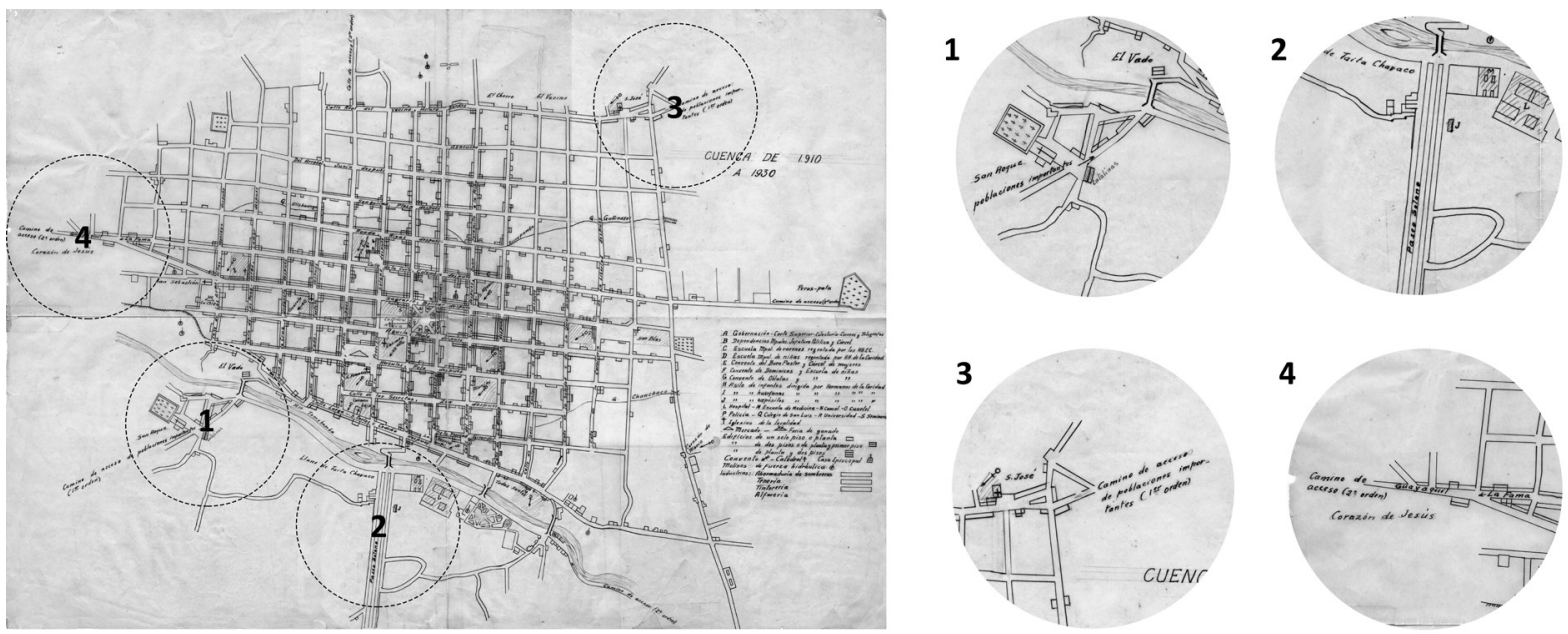

Fuente: Albornoz, 2008. Autor: No identificado. Edición propia. 
FIGURA 9.

PLANOS DE LA CIUDAD DE CUENCA, 1942 Y 1963

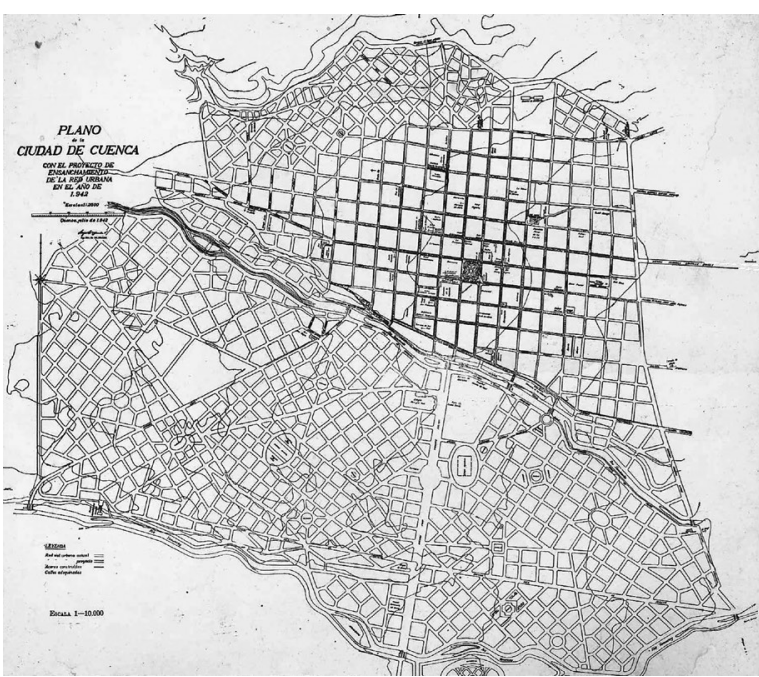

Fuente: Albornoz, 2008

no se puede identificar justamente por la presencia de la avenida. Esta zona es producto de la ocupación de un entorno rural debido a la expansión de la ciudad. Aquí, se inaugura una nueva forma de desarrollo para Cuenca que transforma el paisaje rural en urbano; anticipa la modernización definitiva que da lugar a la ciudad extendida, resultado de los sucesivos planes de ordenamiento. Las infraestructuras viales emergen como elementos estructuradores de la nueva forma general; la conexión entre la ciudad central y distintas áreas de expansión queda articulada por un conjunto jerarquizado vial fuertemente dominado por la avenida Fray Vicente Solano como hito emblemático de progreso. Este eje vial es una expresión material de la transformación de la ciudad y de nuevas formas de habitar.

La Figura 9 muestra dos planos que permiten apreciar lo antes mencionado. El primero dibujado en 1942, es una propuesta de ensanche de la ciudad, especialmente hacia la zona sur de El Ejido (Albornoz, 2008). Sin embargo, no es sino hasta después de mediados de siglo, que esta zona empieza a configurarse y consolidarse. El segundo plano de 1963, refleja el verdadero crecimiento de la época. Se observan algunos de los equipamientos y avenidas principales que darían inicio a la consolidación de El Ejido, con la avenida Fray Vicente Solano como eje principal. Actualmente esta avenida es una de las más importantes y concurridas de la ciudad.

Transformación en los paisajes urbanos de Cuenca: calle Simón Bolívar y avenida Fray Vicente Solano

En las Figuras 10 y 11 que datan de 1920 a 1926 aproximadamente, es interesante observar cómo varios sis-

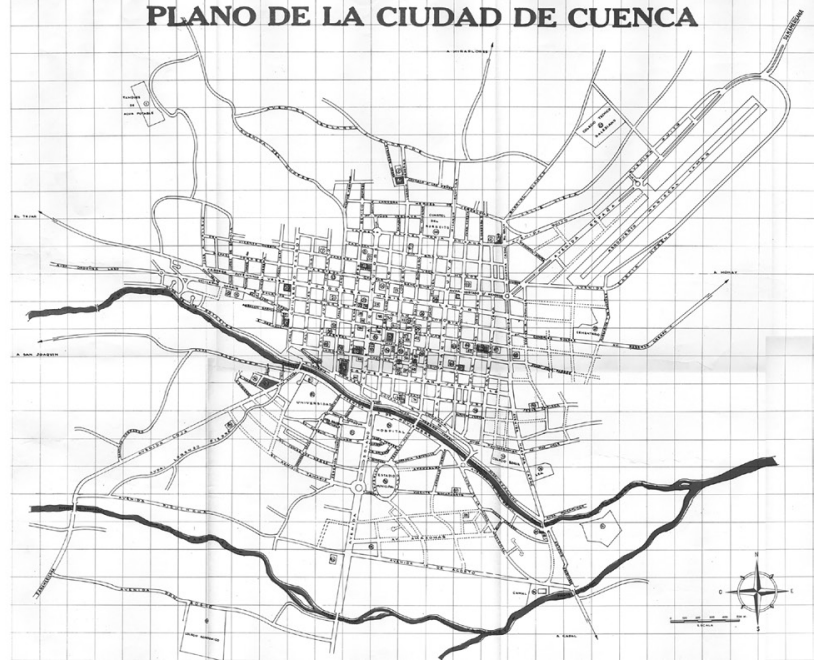

temas de iluminación correspondientes a distintos periodos conviven y se sobreponen en una misma imagen urbana. Se observa que en un primer momento aparece el sistema de iluminación con lámparas a base de petróleo. Luego, en la misma escena, se observa cómo se incorpora el sistema de iluminación al costado de la vía con postes de madera y cableado aéreo. En la tercera imagen, se evidencia cómo el sistema de iluminación mejora con postes más elevados de alta tensión y cables. Asimismo, se observa el sistema de canalización a cielo abierto a los costados de la vía, siendo un procedimiento aún precario y nada estético para el paisaje de la ciudad. Seguramente, de aquellos canales emanaban olores desagradables, y su escasa higiene causaba problemas de salud a los habitantes; aun así, se observa que los ciudadanos caminan o descansan junto a ellos, formando parte de su día a día. Estas transformaciones supondrían también cambios en los modos de vida de los habitantes que, por ejemplo, empezarían a adquirir nuevos artefactos domésticos eléctricos para los diferentes quehaceres del hogar; o que harían uso de las radios eléctricas para informarse y ya no solo de la prensa escrita.

Por otro lado, como se observa en las fotografías, en este periodo las calles eran empedradas, aptas para los peatones y carruajes; sin embargo, en la Figura 11 se aprecia la presencia del vehículo motorizado circulando por la vía. La introducción del vehículo en la ciudad por su parte, significaría el cambio en los modos de transporte de los ciudadanos. Los traslados a pie o en carruaje se verían disminuidos cada vez, así como el espacio viario destinado para estos fines, siendo 
FIGURA 10.

CALLE SIMÓN BOLÍVAR, VISTA HACIA EL OESTE, 1920-26

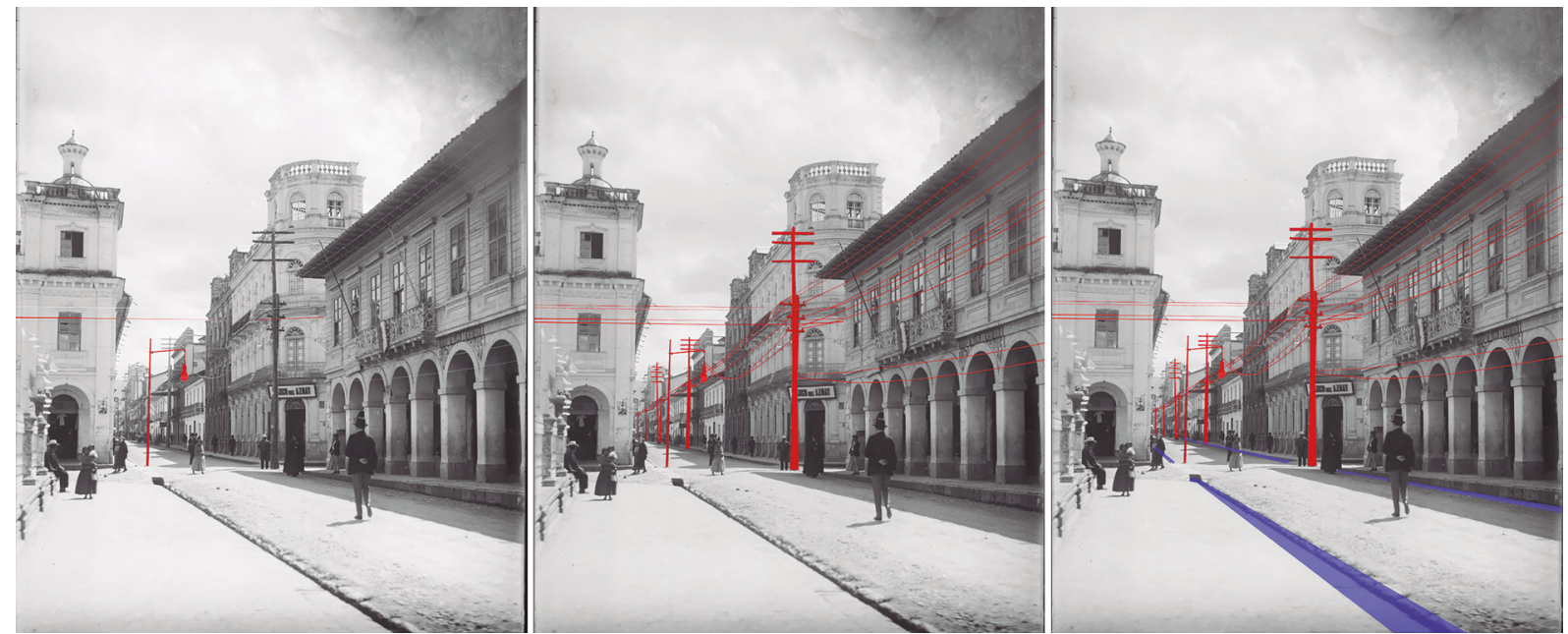

Fuente: Colección Julio Enrique Estrada Ycaza. Edición propia.

FIGURA 11.

CALLE SIMÓN BOLÍVAR, VISTA HACIA EL ESTE, 1920-26
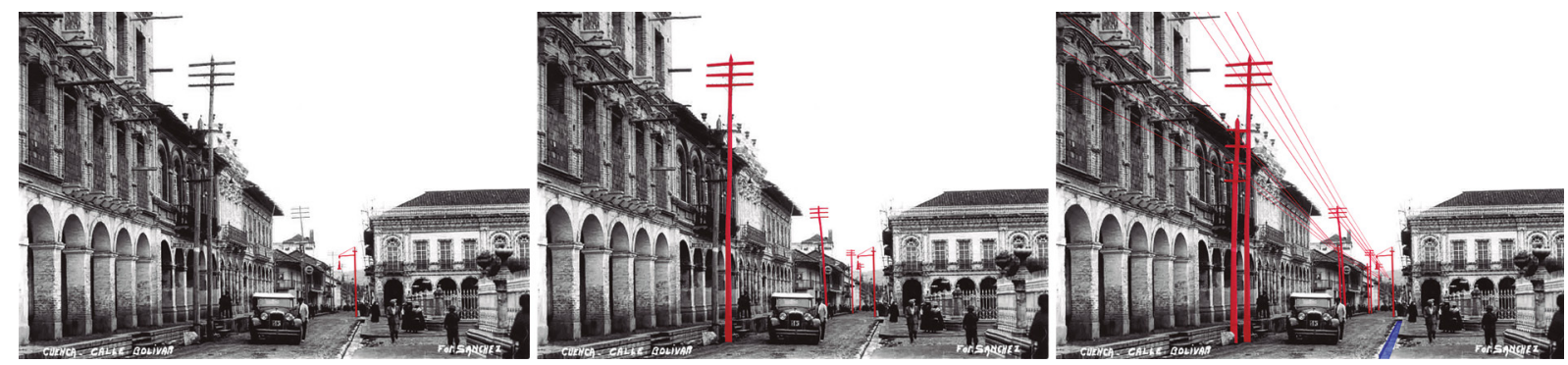

Fuente: Fondo Nacional de Fotografía. Edición propia.

FIGURA 12.

CALLE SIMÓN BOLÍVAR Y PLAZA CENTRAL, VISTA HACIA EL ESTE, 1930
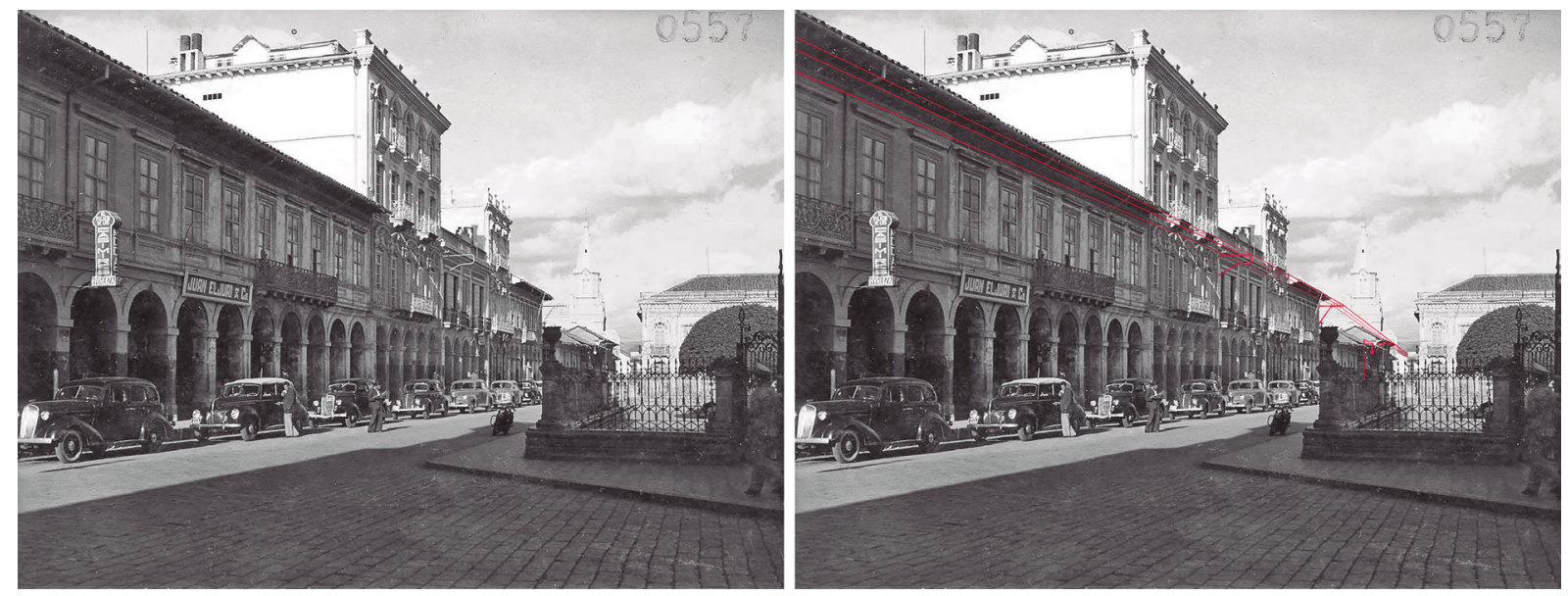

Fuente: Fondo Nacional de Fotografía. Edición propia. 
luego prioridad para el sistema de calles, el vehículo motorizado.

Lo descrito se hace evidente en la Figura 12 que corresponde a calle Simón Bolívar en la década de los 30. Se observa como los sistemas de iluminación anteriormente identificados son reemplazados por un sistema de conducción por empotramiento en fachada con cables aéreos. Para este periodo, el sistema de canalización a cielo abierto es sustituido por el sistema de canales cubiertas, por lo que ya no se observan zanjas en la vía. Eso significaría una imagen más higiénica de la ciudad, y el cambio del sistema de evacuación de aguas servidas al interior de las viviendas. Por otro lado, el material de la calzada que anteriormente era de piedra, ahora es de adoquín. Es notoria la prioridad que se le dio al vehículo privado y el aumento de su presencia en las calles, mientras que el número de peatones es casi nulo. Así, las trasformaciones del paisaje urbano, van de la mano con cambios en los modos de ser y hacer de sus habitantes.
Mientras en el centro de la ciudad ya consolidado, representado en este documento por la calle Simón Bolívar, se observa una mejora de los sistemas y servicios, la avenida Fray Vicente Solano y la zona de El Ejido muestran un desarrollo distinto. Durante la primera mitad del siglo XX, en este sector se aprecia una transformación del paisaje rural en urbano. Los primeros años del siglo, la avenida Fray Vicente Solano era apenas un camino que se extendía hacia el sur, sin infraestructura todavía (Fig. 13). La imagen muestra un entorno rural, con amplia extensión de vegetación, bosques, tierras de cultivo $y$, aparentemente, bastante alejado del núcleo consolidado. Los modos de vida de esta zona estaban vinculados con las actividades del campo, aun sin una fuerte influencia de la vida urbana que pronto se haría presente.

Con el avance del siglo, se comienza a dotar de infraestructura a esa zona tanto de energía eléctrica como de agua potable y alcantarillado. Los cambios fueron paulatinos pero contundentes; por ejemplo,

FIGURA 13.

CONTEXTO GENERAL DE LA AVENIDA FRAY VICENTE SOLANO SIN INFRAESTRUCTURA, VISTA HACIA EL NORTE 19151925 APROXIMADAMENTE

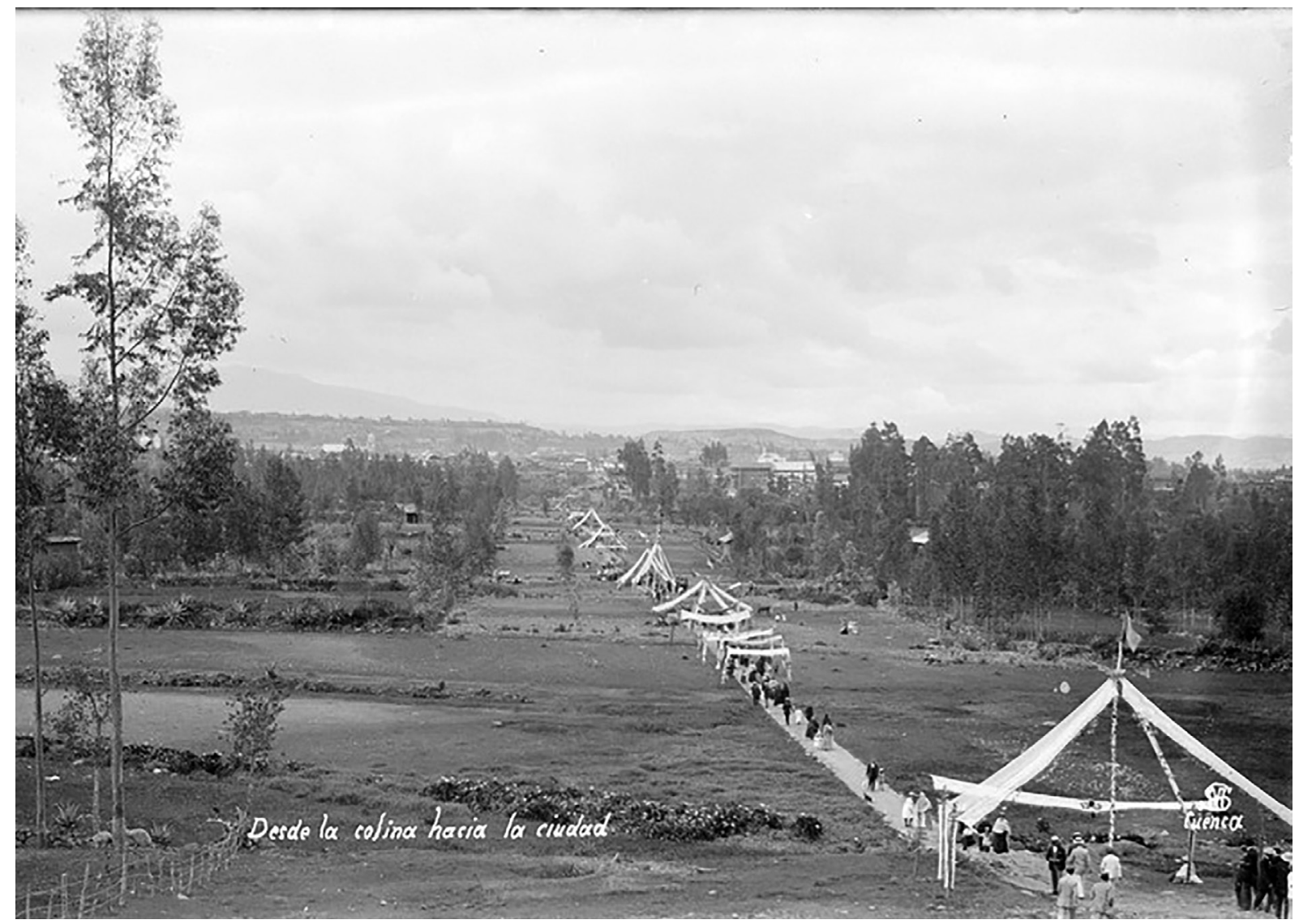

Fuente: Fondo Nacional de Fotografía. 
FIGURA 14.

AVENIDA FRAY VICENTE SOLANO, VISTA HACIA EL SUR, 1935-45

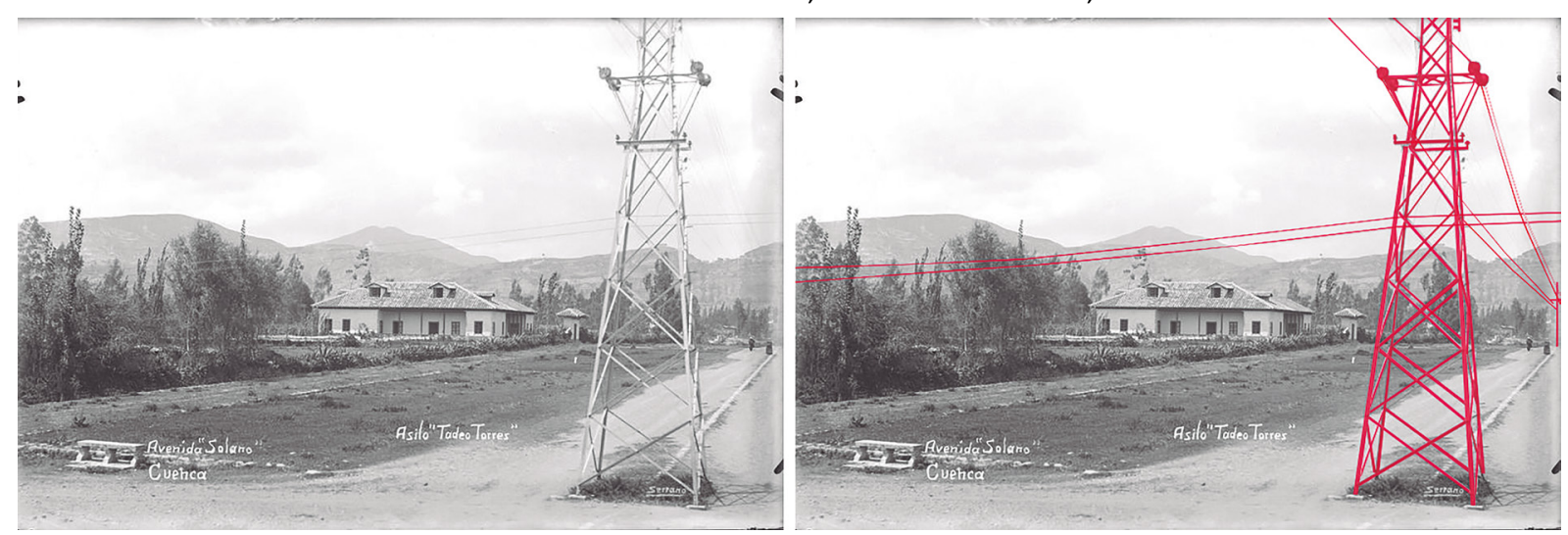

Fuente: Fondo Histórico Fotográfico Museo Pumapungo. Edición propia.

FIGURA 15.

AVENIDA FRAY VICENTE SOLANO, VISTA HACIA EL SUR, 1940-50
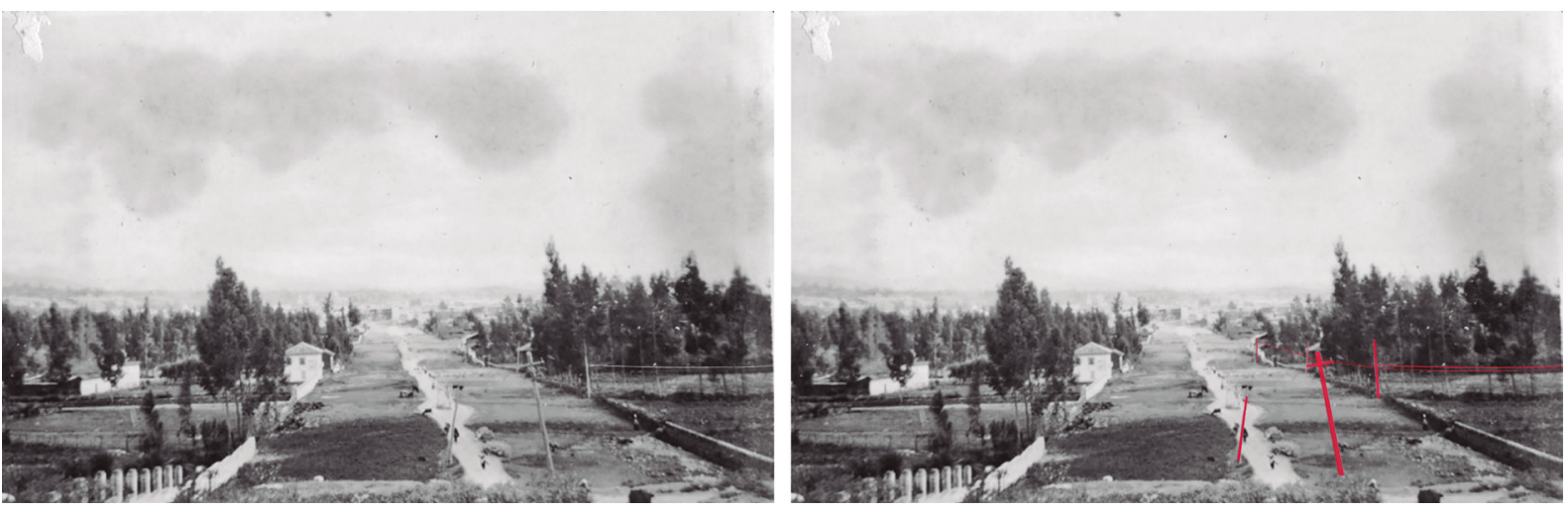

Fuente: Fondo Histórico Fotográfico Museo Pumapungo. Edición propia.

FIGURA 16.

AVENIDA FRAY VICENTE SOLANO, VISTA HACIA EL SUR, 1960
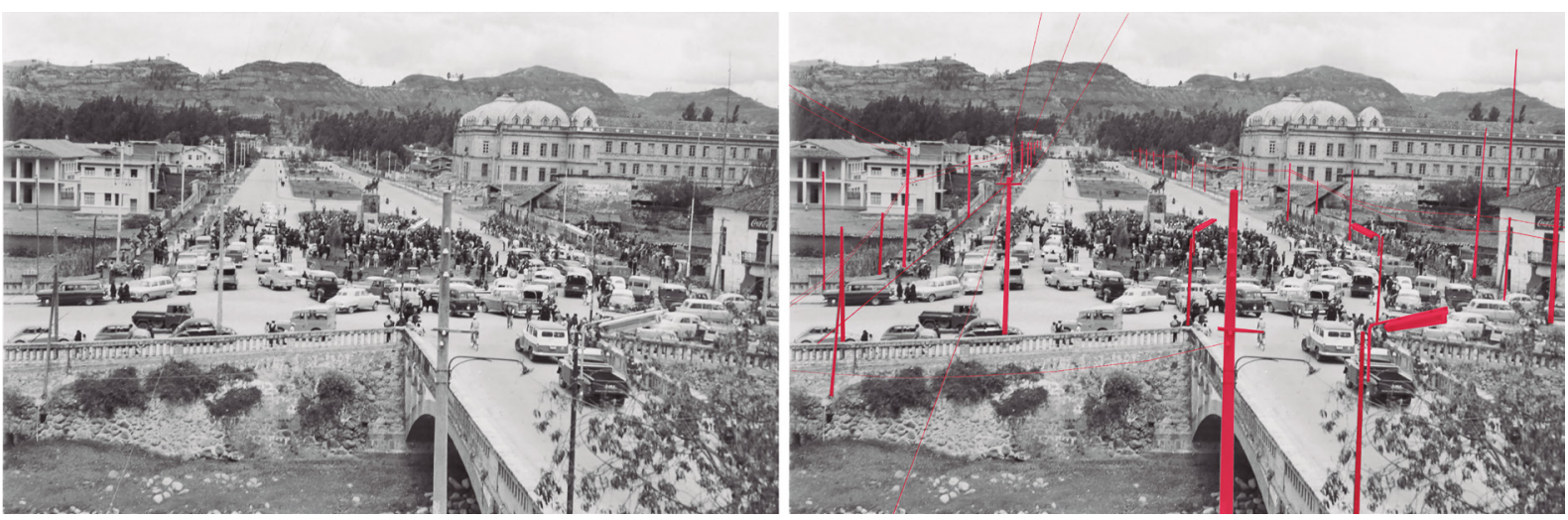

Fuente: Fondo Histórico Fotográfico Museo Pumapungo. Edición propia. 
la Figura 14 muestra la incorporación de la torre de transmisión como un elemento de gran magnitud y seguramente impactante en el contexto emplazado. Sin embargo, la calzada sigue siendo angosta y de tierra, el entorno se muestra poco consolidado y no hay rastro de trabajos de canalización. El paisaje sigue dominado por árboles y vegetación, y apenas se observan algunas edificaciones, mientras al fondo las montañas sobresalen enmarcando el paisaje.

Para la década de los 40 , se observa la incorporación de postes para iluminación al centro de la vía (Fig. 15) y un ensanchamiento de la calzada que se adecúa para dos carriles vehiculares, pero continúa siendo de tierra. En cuanto al contexto, es notoria la disminución de vegetación y el incremento de edificaciones en la zona; a pesar de ello, el entorno todavía se vislumbra rural y lejano. Se podría pensar que, aunque los modos de vida estaban aun ligados a las actividades del campo, existía ya una fuerte presencia de la vida urbana, y una relación cada vez más estrecha con la Cuenca consolidada. Las imágenes invitan a imaginar las grandes transformaciones que estarían próximas a suceder en forma tangible e intangible.

Entre los años 50 y 60 (Fig.16), se puede observar como el paisaje que anteriormente se mostraba rural y atrasado en términos de infraestructura, ha cambiado radicalmente. Por un lado, se observa una avenida imponente, ensanchada y pavimentada que marca un eje de crecimiento hacia el sur; por otro, se observan nuevas edificaciones que se levantan a lo largo de la calzada en sus dos costados. Del mismo modo, se identifican postes de luz y cables conductores de energía eléctrica que discurren de norte a sur, lo que sugiere que las nuevas edificaciones contarían ya con instalaciones eléctricas conectadas a esta red. En cuanto a la canalización, esta es subterránea por lo que no hay rastro de canales o zanjas. Se aprecian, además, una gran cantidad de vehículos circulando por la avenida. Es claro como el paisaje anteriormente rural, adquiere ahora un carácter urbano y moderno. Las nuevas infraestructuras dejan en el pasado las actividades del campo y adecúan la zona para la expansión de la ciudad. Una gran avenida se superpone dando prioridad a los modos motorizados de transporte, dejando atrás los carruajes y caballos. Sin duda alguna, esta imagen representa el gran salto dado entre inicios y medidos del siglo en Cuenca, y cómo las infraestructuras y su evolución, transformaron progresivamente el paisaje urbano y los modos de vivir.

\section{Discusión}

Mirar el pasado, permite comprender aquellas transformaciones en el paisaje urbano causadas por la incorporación de nuevas infraestructuras y servicios. El estudio además de mostrar los cambios que son evidentes en el paisaje de Cuenca durante la primera mitad del siglo XX, refleja el crecimiento de la ciudad e interpreta aquellos factores tecnológicos, económicos, sociales y culturales que han incidido para que dichas transformaciones paisajísticas sucedan. Un factor determinante en los cambios del paisaje en Cuenca, ha sido el poder socio-económico de algunas élites que han instaurado ideales en la sociedad, y en algunos casos, han asignado recursos para que estos ideales sean materializados. En este sentido, las actividades socioeconómicas producto de la exportación de la cascarilla y la paja toquilla, han sido elementos clave en el desarrollo urbano de Cuenca.

De esta manera, las infraestructuras y su incidencia en el paisaje se manifiestan en dos formas distintas que adoptan condiciones o respuestas diferenciadas en función de las características morfológicas y cualidades espaciales y del paisaje donde se desarrollan. Por un lado, se incorporan y evolucionan en el centro histórico ya consolidado, y por otro, dan inicio a la urbanización de la zona de El Ejido, que en ese entonces era considerada de expansión y de carácter rural. Así, se originan dos realidades espaciales, una de acoplamiento a lo construido y otra de planificación integral. En el primer caso, las infraestructuras respetan la escala de la ciudad y sus características fundamentales. Se evidencian actualizaciones o sustituciones en aspectos referidos a electrificación, canalización y alcantarillado, que casi siempre suceden simultáneamente y son desarrollados en paralelo. En el segundo caso, se observa como el entorno rural recibe a estas infraestructuras y son ellas quienes dan inicio a la consolidación de esta zona.

Conjuntamente con los cambios visibles del paisaje, las nuevas infraestructuras condicionan las prácticas sociales que intervienen históricamente en los dos sectores de la urbe. En el centro histórico, por ejemplo, la instalación del servicio de agua potable entubada significó que las personas dejen de salir de sus casas para proveerse de este recurso, y que el aseo pueda hacerse en espacios adaptados para ello al interior de la vivienda. Asimismo, la electricidad permitió que actividades como escuchar la radio, leer, cocinar, entre otras, se puedan realizar con facilidad y en horas antes no acostumbradas. Por otro lado, la pavimentación de las calles y la importación de vehí- 
culos transformaron los modos de transporte, pero también permitieron que la comunicación y el transporte de bienes y personas sean más rápidos y efectivos. Por su parte, los habitantes de la zona de El Ejido, debían adaptarse a las nuevas infraestructuras y a la urbanización de esta área, modificando sus prácticas rurales (ganadería, agricultura, etc.), por otras labores y hábitos de la vida urbana. Estos sucesos, también forman parte del paisaje y los imaginarios que se tienen de él.

Por lo tanto, el desarrollo urbano se inscribe en un contexto de mejora integral, en donde prima la racionalidad como emblema de la modernización urbana, en una planificación cuya lógica viene dictada por la funcionalidad y las necesidades de salubridad e higiene. Se busca lograr un óptimo equipamiento en infraestructuras y servicios en relación a una red de transportes y comunicaciones integrada hacia el exterior; ligadas a otras transformaciones complementarias, tanto en el plano espacial como en el habitacional.

\section{CONCLUSIONES}

Son varios los aportes de este estudio en torno a las distintas formas de abordar el análisis del paisaje urbano y sus transformaciones en la historia. Por un lado, se demuestra el valor documental y el potencial de las imágenes históricas para los estudios de ciudad asociados al paisaje, corroborando con trabajos previos que utilizan la fotografía histórica como herramienta de investigación. Por otro, se evidencian los momentos significativos de cambio y transformación en la ciudad de Cuenca durante la primera mitad del siglo XX. Estos cambios están asociados a la incorporación e innovación de infraestructuras y redes de servicios básicos de agua y alcantarillado, así como a la implementación de energías (petróleo y electricidad). También, se describe cómo estos sistemas surgen asociados a procesos de planificación urbana y se interpreta de qué manera influyeron en las formas de vivir.

Con evidencia gráfica del proceso de transformación de la urbe, se manifiesta la importancia de las imágenes como fuentes complementarias y fiables para aportar en la construcción de la memoria colectiva de la sociedad. Se planteó una aproximación desde la fotografía histórica, que registra una visión de aquella realidad en su momento, como hilo conductor que oriente los procesos y dé cuenta de las transformaciones. Estos recorridos por las imágenes permitieron construir una línea temporal a partir de aquellas miradas que captaron momentos trascendentes y sig- nificativos, y plasmaron en imágenes los paisajes y los procesos de transformación urbana.

Del trabajo investigativo se concluye que los años 20 marcaron un punto de inflexión con el inicio de una renovación modernizadora en el país y específicamente en Cuenca. Esto fue producto del auge económico y el florecimiento cultural, que se fortaleció con los discursos modernizadores e higienistas promovidos por el estado; hechos que alentaron la incorporación y dotación de servicios públicos por entidades municipales. Aquellas circunstancias despertaron un ímpetu progresista que marcaría inevitablemente el paisaje de Cuenca. A inicios del siglo XX, se evidencian momentos de particular relevancia; se da un salto cualitativo en las infraestructuras producto de dos eventos socio-económicos claves: la explotación de cascarilla y la producción y exportación de sombreros de paja toquilla. Los cuales, se convierten en motor para la dotación e incorporación de nuevas energías, infraestructuras y adelantos tecnológicos, en busca de mejorar la calidad de vida de sus habitantes. Esto permitió que las distintas formas de drenajes y abastecimiento de agua, se desarrollaran en simultáneo con medios de distribución del servicio eléctrico, con sistemas de iluminación y comunicación, así como con los soportes para los requerimientos de transporte. Todos estos sistemas modificaron en conjunto y sistemáticamente el paisaje urbano existente en la zona consolidada, y transformaron el paisaje rural en urbano en la zona de expansión.

Los resultados de esta investigación dan luces sobre los cambios que las infraestructuras generaron en su momento en el paisaje y modos de vida en Cuenca, y cómo los nuevos sistemas de infraestructuras y redes inteligentes de energía podrían afectar los paisajes naturales y urbanos presentes y futuros, y la forma de vida de las sociedades. Profundizar en los temas tratados en este documento es imprescindible, pues el paisaje urbano está cambiando constantemente y cada vez a un paso más acelerado con las nuevas tecnologías. Se debería preguntar, por ejemplo, ¿cómo las energías renovables del siglo XXI, que incluyen paneles solares, hélices eólicas y una serie de dispositivos están transformando el paisaje urbano? ¿Cómo estos cambios están influyendo en los modos de ser y hacer de la sociedad y cómo estamos respondiendo a ellos? Estas, entre otras interrogantes, abren la posibilidad a nuevas investigaciones que utilicen métodos visuales, incluyendo fotografía y re-fotografía al momento presente y futuro, y que permitan generar reflexiones y respuestas oportunas frente a estas situaciones. 


\section{REFERENCIAS BIBLIOGRÁFICAS}

Albornoz, B. (2008). Planos e imágenes de Cuenca. Cuenca, Ecuador: Ilustre Municipalidad de Cuenca.

Arreola, D. D. y Burkhart, N. (2010). Photographic postcards and visual urban landscape. Urban Geography, 31(7), 885-904. doi: 10.2747/02723638.31.7.885

Astudillo, J. S. (2008). Geografía del Paisaje. Estudio y valoración de la calidad del paisaje en el Barranco de la ciudad de Cuenca (Tesis de maestría). Universidad de Cuenca, Ecuador.

Borrero, A. L. (2006). Cambios históricos en el paisaje de Cuenca, siglos XIX-XX. Procesos. Revista ecuatoriana de historia, 1(24), 107-134. doi: 10.29078/ rp.v1i24.208

Brito, E. S. y Espinoza, D. C. (2018). Transformación de calles y espacios interiores de la vivienda debido a la incorporación de la infraestructura de agua y saneamiento durante el siglo XX en Cuenca (Tesis de pregrado). Universidad de Cuenca, Ecuador. Recuperado de http://dspace.ucuenca.edu.ec/ handle/123456789/31596

Burke, P. (2001). Eyewitnessing: The uses of images as historical evidence. Ithaca, NY: Cornell University Press.

Claval, P. (2012). A paisagem dos Geógrafos. En R. L. Corrêa y Z. Rosendahl (Ed.), Geografia cultural: uma antología, Volumen 1 (pp.245-276). Rio de Janeiro, Brasil: EDUERJ.

Cuenca, su historia: al paso de los siglos XIX y XX. (2014). El Telégrafo. Recuperado de http://www. eltelegrafo.com.ec/noticias/regional-sur/1/cuenca-su-historia-al-paso-de-los-siglos-xix-y-xx

Ferrer, A. (2009). Paisajes urbanos. En J. Busquets y A. Cortina (Coord.), Gestión del paisaje: manual de protección, gestión y ordenación del paisaje (pp. 41-60). Barcelona, España: Ariel.

Foote, K. E. (1985). Velocities of change of a built environment, 1880-1980: Evidence from the photoarchives of Austin, Texas. Urban Geography, 6(3), 220-245. doi: 10.2747/0272-3638.6.3.220

Foote, K. E. (1986). Documentary photography and questions of urban change. Urban Geography, 7(5), 462-468. doi: 10.2747/0272-3638.7.5.462

Fürstenau, H. (2009). Interpretação da paisagem: uma tarefa interdisciplinar. Cuadernos de Geografía:
Revista Colombiana de Geografía, (18), 71-81. doi: 10.15446/rcdg.n18.13021

Gürel, M. Ö. (2008). Bathroom as a modern space. The Journal of Architecture, 13(3), 215-233. doi: $10.1080 / 13602360802214943$

Instituto Nacional de Estadísticas y Censos - INEC (2010). Censo de Población y Vivienda. Ecuador. Recuperado de https://www.ecuadorencifras. gob.ec/censo-de-poblacion-y-vivienda/

Kingman, E. (2006). La ciudad y los otros. Quito 1860-1940. Higienismo, ornato y policía. Quito, Ecuador: FLACSO. Recuperado de https:// biblio.flacsoandes.edu.ec/shared/biblio_view. php?bibid $=100133 \&$ tab $=$ opac

Klett, M. y Lundgren, M. (2006). After the Ruins, 1906 and 2006: Rephotographing the San Francisco Earthquake and Fire. San Francisco, CA: Museum of Fine Arts and University of California Press..

Lloret, A. (2015). Biografía de Cuenca. Tomo 1. Cuenca, Ecuador: GAD Municipal del cantón Cuenca.

Mancero, M. (2010). De Cuenca Atenas a Cuenca Patrimonio: estrategias de distinción en la construcción del Estado-Nación. En F. Burbano (Coord.), Transiciones y rupturas. El Ecuador en la segunda mitad del siglo XX (pp. 197-246). Quito, Ecuador: FLACSO y Ministerio de Cultura (Colección Bicentenario). Recuperado de https://biblio.flacsoandes.edu.ec/libros/digital/52586.pdf

Manfredi, M. (2008). La fotografía como fuente para el análisis de los procesos migratorios: metodología, conceptualización y crítica en la historia de la emigración vasca a Uruguay (siglos XIX-XX) (Tesis doctoral). Universidad del País Vasco-Euskal Herriko Unibertsitatea.

Marchán, C. (1987). Crisis y cambio de la economía ecuatoriana en los años veinte. Quito, Ecuador: Banco Central del Ecuador.

Martínez, J. (2004). La autorepresentación en el campo social de Cuenca de 1901 a 1924. Una aproximación desde la historia visual. Ponencia presentada en el marco del IV Congreso Ecuatoriano de Historia, Cuenca. Recuperado de https://www.academia.edu/6662932/La autorepresentaci\%C3\%B3n_en_el_campo_social_en_Cuenca_entre_1901_y_1924

Moreno, O. (2009). Arquitectura del Paisaje: Retrospectiva y prospectiva de la disciplina a nivel global 
y latinoamericano. Enfoques, tendencias, derivaciones. Revista de Arquitectura, 15(19), 6-13. doi: 10.5354/0719-5427.2013.27994

Notteboom, B. (2011). Recollecting Landscapes: landscape photography as a didactic tool. $A R Q-A R C H I-$ TECTURAL RESEARCH QUARTERLY, 15(1), 47-55. Recuperado de http://hdl.handle.net/1854/LU1227685

Notteboom, B. y Uyttenhove, P. (2018). Recollecting landscapes: rephotography, memory and transformation, 1904-1980-2004-2014. Ámsterdam, Países Bajos: Roma Publications.

Novillo, M. A. (2010). Estudio histórico y cultural de Cuenca en el siglo XX (1920-1980), a partir de la producción literaria de G.H. Mata (Tesis de pregrado). Universidad de Cuenca, Ecuador. Recuperado de http://dspace.ucuenca.edu.ec/handle/123456789/1937

Page, B. (2007). Beijing: Then and Now. San Diego, CA: Thunder Bay Press.

Rodas, C. M., Astudillo, J. S., y Rodas, J. (2018). En busca del equilibrio entre transformación y conservación. Inserción de proyectos contemporáneos en ciudades patrimonio de la humanidad: el caso de Cuenca, Ecuador. ASRI: Arte y sociedad. Revista de investigación, (14), 215-235. Recuperado de https://dialnet.unirioja.es/servlet/ articulo?codigo $=6266269$

Rueda, J. C. (2001). La imagen de la ciudad y el paisaje urbano. Arbor, 169(666), 303-322. doi: 10.3989/ arbor.2001.i666.885
Sansolo, D. G. (2007). Significados das paisagens como categoria de análise geográfica. Niterói: ANPEGE.

Spedding, N. (2003). Landscape and Environment: Biophysical Forms. En S. Holloway, P. Rice y G. Valentine (Ed.), Key Concepts in Geography (pp. 281304). Londres, Inglaterra: Sage.

Troll, C. (1963). Ecología del paisaje. En J. Mendoza et al. (Ed.), El pensamiento geográfico (pp.465-469). Madrid, España: Alianza Editorial.

Vintimilla, S. T. (2019). Identificación y valoración de visuales relevantes en el Paisaje Urbano Histórico de Cuenca: caso de estudio El Ejido (Tesis de maestría). Universidad de Cuenca, Ecuador. Recuperado de http://dspace.ucuenca.edu.ec/handle/123456789/32222

Zoido, F. (2006). Paisaje e infraestructuras, una relación de interés mutuo. Carreteras: Revista técnica de la Asociación Española de la Carretera, (150), 190-199. Recuperado de http://www.upv.es/contenidos/CAMUNISO/info/U0581071.pdf.

Zoido, F. (2012). Paisaje urbano. Aportaciones para la definición de un marco teórico, conceptual y metodológico. En C. Delgado, J. Juaristi y S. Tomé (Ed.), Ciudades y paisajes urbanos en el siglo XXI (pp. 13-92). Santander, España: Librería Estudio.

Zubelzu, S. y Allende, F. (2015). El concepto de paisaje y sus elementos constituyentes: requisitos para la adecuada gestión del recurso y adaptación de los instrumentos legales en España. Cuadernos de Geografía: Revista Colombiana de Geografía, 24(1), 29-42. doi: 10.15446/rcdg.v24n1.41369 